\title{
Infrared-Transparent Glass Ceramics: an Exploratory Study
}

\author{
John S. McCloy, ${ }^{1 *}$ Brian J. Riley, ${ }^{2}$ David A. Pierce ${ }^{2}$ \\ ${ }^{1}$ Washington State University, Pullman, WA 99163 \\ ${ }^{2}$ Pacific Northwest National Laboratory, Richland, WA 99352
}

Keywords: glass-ceramic; infrared-transparent; chalcogenide; phase separation; $\mathrm{La}_{2} \mathrm{~S}_{3}$

\begin{abstract}
In this work, the vision and need for a fully ceramized long-wave infrared (LWIR)-transmitting glass ceramic has been articulated. Three sulfide systems were explored including two with $\mathrm{La}_{2} \mathrm{~S}_{3}$ in hopes of imparting strong bonds from this refractory sulfide, and two containing $\mathrm{GeS}_{2}$ in hopes of widening the glass-forming region. Attempts were made to produce glasses in the $\mathrm{Ga}_{2} \mathrm{~S}_{3}-\mathrm{La}_{2} \mathrm{~S}_{3}-(\mathrm{ZnS}, \mathrm{CaS})$ system, the $\mathrm{GeS}_{2}-\mathrm{La}_{2} \mathrm{~S}_{3}$ system, and the $\mathrm{GeS}_{2}-\mathrm{Ga}_{2} \mathrm{~S}_{3}-\mathrm{CdS}$ system. Water quenching produced glasses of $\mathrm{Ga}_{2} \mathrm{~S}_{3}-\mathrm{La}_{2} \mathrm{~S}_{3}-\mathrm{CaS}$ and $\mathrm{GeS}_{2}-\mathrm{Ga}_{2} \mathrm{~S}_{3}-\mathrm{CdS}$. Microstructural and thermal analyses were used to explore nucleation and growth in these systems and infrared transmission and mechanical hardness showed potential for LWIR window use. The $\mathrm{GeS}_{2}$ $\mathrm{Ga}_{2} \mathrm{~S}_{3}-\mathrm{CdS}$ system showed good LWIR transmission and pre-crystallized hardness superior to chemical vapor deposited $\mathrm{ZnS}$. The $\mathrm{Ga}_{2} \mathrm{~S}_{3}-\mathrm{La}_{2} \mathrm{~S}_{3}$ glasses did not appear to be viable candidates at this time due to a small temperature window between crystallization and glass transition temperatures and problems with oxygen contamination in the $\mathrm{La}_{2} \mathrm{~S}_{3}$ source. Suggestions are made for two alternative methods for producing fully ceramized LWIR-transmitting glass ceramics.
\end{abstract}

\footnotetext{
* Author to whom correspondence should be addressed, Ph: 509-335-7796; Fax: 509-335-4662; email: john.mccloy@wsu.edu.
} 


\section{Introduction}

For many years, chemical vapor deposited (CVD) $\mathrm{ZnS}$ has been the benchmark longwave infrared (LWIR)-transmitting material, and various attempts have been made to develop ceramic materials with improved engineering properties [1]. Attempts to best $\mathrm{ZnS}$, however, have thus far failed, and $\mathrm{ZnS}$ is still the ideal material for combined thermo-mechanical and optical performance [2]. Yet drive for improvement continues, since mechanical durability of $\mathrm{ZnS}$ is sub-optimal, and reduced cost is always desirable. Several candidate polycrystalline ceramics have been developed with the intent of replacing $\mathrm{ZnS}$, but no material has been successful, due poor thermal properties, degraded optical transparency, or excessive cost. [1,3].

The aforementioned contenders for replacing $\mathrm{ZnS}$ as a durable LWIR ceramic invariably were produced with traditional ceramic powder processing or CVD. A potential alternative for making durable LWIR ceramics may lie in the use of a glass-ceramic process for making nanocomposites. Compared to traditional powder ceramic processing, glasses and glass ceramics are typically easier to form and have equal or greater potential for process scaling. By definition, glass ceramics are multiphase polycrystalline materials which were once amorphous glasses produced using one of several traditional glass-forming processes. These glasses are then cooled and subsequently heat-treated through a proscribed schedule to enable controlled nucleation and growth of crystalline phases. Durable LWIR-transmitting ceramics could conceivably be produced from such glasses, provided that the ultimate crystalline phases are themselves LWIR transparent and are sufficiently small such that scattering due to refractive index mismatch is minimized. Ideally, glass ceramics which have crystallized fully should provide the best hardness and fracture toughness. Various applications have been proposed for infrared-transmitting glass ceramics including bulk optical elements $[4,5]$, far-infrared 
transmitting optical fibers [6], devices utilizing nonlinear optical behavior [7, 8], and inorganic scintillators for high energy detectors [9-11].

This paper summarizes previous work on infrared glass-ceramic systems and justifies the selection of a few candidate systems for LWIR glass ceramics. Additionally, preliminary studies are presented for making glasses in three systems containing $\mathrm{Ga}_{2} \mathrm{~S}_{3}$ and/or $\mathrm{GeS}_{2}$, including glassforming ability, microstructure, thermal properties, infrared transmission, and mechanical hardness. Finally, the suitability of these systems for future work on LWIR glass ceramics is discussed.

\section{Background and Approach}

\subsection{Previous work on IR glass-ceramic systems}

The goal of the current work is to evaluate glass ceramics in search of a product with potentially superior mechanical strength and LWIR transparency compared to CVD ZnS. It is assumed that such a glass ceramic should be fully crystalline (except minor glassy phase at grain boundaries typical of ceramics) with grain size $\lesssim 0 \mathrm{~nm}$. Glass ceramics meeting these requirements have thus far been produced only in a few oxide systems, notably Al-(La, Gd, Y)Zr-O (grain size $\sim 100 \mathrm{~nm}$ ) [12] and Ba-Al-O (grain size $500-5000 \mathrm{~nm}$ ) [13]. One oxide system previously investigated specifically for use as a bulk ceramic window for the midwave infrared (MWIR, $3-5 \mu \mathrm{m}$ ) is based on Ba-Ga-Ge-O glasses [5] containing a small volume fraction of $\mathrm{BaGe}_{4} \mathrm{O}_{9}$ crystals [4]. Many other glass ceramic oxides are commercially important, but these generally consist of a glassy matrix embedded with a low to medium volume fraction $(<40 \%)$ of $<100 \mathrm{~nm}$ crystals. Examples include aluminosilicates such as mullite, cordierite, and $\beta$-quartz derivatives (e.g., $\beta$-eucryptite), and others such as oxyfluorides and spinels [14-16]. 
Chalcogenide-based glass ceramics show the best promise for durable LWIR-transmitting ceramics, but systems based on heavy pnictides such as arsenic should be considered as well [3]. Since weaker chemical bonding is associated with improved transparency further into the infrared [1, 17], materials based on Se and Te will have improved LWIR or far-IR transmission, but inferior mechanical properties to analogous materials based on S. However, selenide and telluride precursors typically have higher purity, as sulfur raw material is typically contaminated with oxygen, carbon, and metal-oxygen bonds [18] and these impurity species absorbing strongly in MWIR and/or LWIR regions [19]). Ba-Ga-Ge-X systems (where $\mathrm{X}=\mathrm{S}, \mathrm{Se}$ ), analogous to the aforementioned oxides, have been proposed, with heavier chalcogens acting to increase the infrared transmission cut-off wavelength but decrease the compositional area for glass formation [20].

All sulfide glass-ceramic systems reported in the literature thus far have consisted of a majority of glass phase with a minority of small crystallites. Some glass ceramics, more properly glasses containing crystals, are made inadvertently upon quenching when exploring the compositional dependence of glass-forming in a particular system. Some glass ceramics based on $\mathrm{S}$ have been deliberately designed to improve hardness, but again these are typically low volume fractions of crystals. The exemplar systems are traditional chalcogenide (sulfide) glasses based on $\mathrm{GeS}_{2}$ plus $\mathrm{Ga}_{2} \mathrm{~S}_{3}$ or $\mathrm{Sb}_{2} \mathrm{~S}_{3}$ [21, 22], sometimes including alkali halides [6, 23-25]. When an alkali halide such as $\mathrm{CsCl}$ is included, it is normally the crystalline phase in the glass ceramic, although rarely other phases such as $\alpha-\mathrm{Ga}_{2} \mathrm{~S}_{3}$ are shown to precipitate $[26,27]$.

\subsection{Candidate LWIR glass-ceramic systems}

Based on a literature review, systems containing the glass-forming components $\mathrm{Ga}_{2} \mathrm{~S}_{3}$ and/or $\mathrm{GeS}_{2}$ were determined to be the most promising, and thus were investigated 
experimentally. The expectation was that the addition of the highly refractory $\mathrm{La}_{2} \mathrm{~S}_{3}$ would improve mechanical properties and result in a strong ceramic when crystallized.

The Ga-La-S (GLS) glass composition is commercially available and used for fiber lasers [28]. Glass-forming in GLS is favored when $R=\mathrm{Ga} /(\mathrm{Ga}+\mathrm{La})$ is between 0.5 and 0.8 , by mole [29]. Tailoring the glass with rare-earths, other than La, is possible with a reduction in the glassforming region. Additionally, $\mathrm{Ga}_{2} \mathrm{~S}_{3}$ with sulfides of $\mathrm{Ge}, \mathrm{Sn}, \mathrm{Pb}$, and $\mathrm{Bi}$ is reported to form glass [29]. Oxygen impurities are common in GLS glasses, producing an absorption band in the LWIR near $8.5 \mu \mathrm{m}[30,31]$. Later work has indicated that oxygen impurities in $\mathrm{La}_{2} \mathrm{~S}_{3}$ precursor materials are at least partially responsible for the large glass-forming region of GL(O)S [28, 29]. By itself, GLS may not have sufficient LWIR transparency as the 1-mm thickness cut-off (50\% transmission) is $\sim 10 \mu \mathrm{m}$, hence other components may be needed to stretch the LWIR cut-off wavelength, as GLS transmission may be limited by $\mathrm{Ga}_{2} \mathrm{~S}_{3}$ vibrations [32]. However, some crystalline phases containing elements in GLS are known to have longer LWIR transmission cutoffs, $>12 \mu \mathrm{m}$, including $\mathrm{CaLa}_{2} \mathrm{~S}_{4}, \mathrm{ZnGa}_{2} \mathrm{~S}_{4}$, and oxygen-free $\mathrm{La}_{2} \mathrm{~S}_{3}$ [28, 33-35]. The current study targets glasses with high enough concentrations of $\mathrm{Zn}$ and/or Ca such that these crystalline phases, in addition to Ga-La-S phases (of which many different crystalline phases exist [36]), might form.

Germanium sulfide can form a glass on its own [37] with a low glass transition temperature $\left(\sim 338{ }^{\circ} \mathrm{C}\right)$ [38] compared to GLS glass $\left(\sim 620^{\circ} \mathrm{C}\right)$ [29], making it attractive for processing as a flux during glass melting. $\mathrm{GeS}_{2}$ reportedly makes a glass in the binary with $\mathrm{La}_{2} \mathrm{~S}_{3}$ [37], and when combined with $\mathrm{Ga}_{2} \mathrm{~S}_{3}$, additional glasses can be formed with multiple sulfides, including $\mathrm{La}_{2} \mathrm{~S}_{3}$ [28], $\mathrm{CdS}$ [39], $\mathrm{CaS}$ [40], $\mathrm{SrS}$ [40], $\mathrm{Ag}_{2} \mathrm{~S}$ [41], and $\operatorname{In}_{2} \mathrm{~S}_{3}$ [32, 42], as well as halides like $\mathrm{CsCl}$ [26]. The glass-forming regions of representative members of these 
systems is illustrated in Figure 1. Compared to $\mathrm{Ga}_{2} \mathrm{~S}_{3}, \mathrm{GeS}_{2}$ is a better glass-former, so making initially crystal-free glasses should be easier even when slow quenching in air. Systems containing $\mathrm{GeS}_{2}$ should have good LWIR transmission but inferior mechanical properties relative to systems without $\mathrm{GeS}_{2}$ due to the weak Ge-S bonds [1, 17].

The $\mathrm{GeS}_{2}-\mathrm{La}_{2} \mathrm{~S}_{3}$ glass binary was of particular interest due to the possibility of strong LaS bonds. The phase diagram from Kumta and Risbud [43] based on data from Sarsikov et al [44] is redrawn in Figure 2, showing a predicted glass forming when $\mathrm{GeS}_{2}$ is $50-100$ mole\%. The approach in the current work is to choose a composition region with two solid phases, make a glass with this composition, and then heat-treat it to form the two crystalline phases. This is a similar approach to that taken for the MWIR nanocomposite optical ceramic system of $\mathrm{Y}_{2} \mathrm{O}_{3^{-}}$ $\mathrm{MgO}$ [45]. The two targeted crystalline phases of Ge-La-S, assumed to be very similar in refractive index, were $\mathrm{La}_{2} \mathrm{GeS}_{5}$ and $\mathrm{La}_{4} \mathrm{Ge}_{3} \mathrm{~S}_{12}$. Monoclinic $\mathrm{La}_{2} \mathrm{GeS}_{5}$ (2-1-5) is reportedly unstable $<600{ }^{\circ} \mathrm{C}$, decomposing into solid $\mathrm{La}_{2} \mathrm{~S}_{3}$ and gaseous $\mathrm{GeS}_{2}$ [46]. The $\mathrm{GeS}_{2}$-rich phase was previously thought to be $\mathrm{La}_{2} \mathrm{Ge}_{2} \mathrm{~S}_{7}$ (2-2-7) [44] but later suggested to be $\mathrm{La}_{4} \mathrm{Ge}_{3} \mathrm{~S}_{12}$ (4-3-12) [46]. In theory then, a glass with composition 55 mole $\% \mathrm{GeS}_{2}$ and $45 \mathrm{~mol} \% \mathrm{La}_{2} \mathrm{~S}_{3}$ could crystallize into roughly equal fractions of $\mathrm{La}_{4} \mathrm{Ge}_{3} \mathrm{~S}_{12}$ and $\mathrm{La}_{2} \mathrm{GeS}_{5}$. Only two specific glasses in this system are known from the recent literature: a heat-treated 60 mole $\% \mathrm{GeS}_{2}$ glass crystallized $\beta-\mathrm{La}_{2} \mathrm{~S}_{3}$, with the $\mathrm{GeS}_{2}$ and some $\mathrm{La}_{2} \mathrm{~S}_{3}$ thought to remain in residual glass; a $\mathrm{GeS}_{2-}$ rich glass, containing 92.5 mole $\% \mathrm{GeS}_{2}$, instead produced only $\mathrm{La}_{4} \mathrm{Ge}_{3} \mathrm{~S}_{12}$ [43]. This existing data illustrates that formation of the $\mathrm{La}_{2} \mathrm{GeS}_{5}$ compound may be difficult, as had been previously suggested [46]. 


\section{Experimental Methods}

\subsection{Raw materials analysis}

All chemicals used in this work were high purity powders (Table I). Upon receipt, they were stored in a nitrogen glovebox to prevent oxygen contamination $\left(\mathrm{O}_{2} / \mathrm{H}_{2} \mathrm{O}<0.1 \mathrm{ppm} ; \mathrm{M}\right.$ Braun, Inc., Stratham, NH). Chemicals were subsequently subjected to a phase-purity analysis with X-ray diffraction (XRD). Note that it was not determined what fractions of the sulfide precursors were crystalline versus amorphous. The results of the phase purity test are shown in Table I. Several items deserve particular note. First, the $\mathrm{GeS}_{2}$ was shown to be a mix of $\mathrm{GeS}$ (orthorhombic Pnma) and $\mathrm{GeS}_{2}$ (monoclinic $\mathrm{P} 2_{1} / \mathrm{c}$ or P12 $1 / \mathrm{c} 1$ [47]), therefore the precise $\mathrm{Ge} / \mathrm{S}$ ratio from this raw material is questionable. The $\mathrm{ZnS}$ sample refinement indicated $\sim 10 \%$ hexagonal $\mathrm{ZnS}$, which is typical for CVD ZnS [2]. The $\mathrm{Ga}_{2} \mathrm{~S}_{3}, \mathrm{CaS}$, and CdS, were phase-pure. The elemental raw materials of $\mathrm{Cd}, \mathrm{Ge}$, and Ga (Alfa Aesar, Ward Hill, MA), and S (ASARCO LLC, Tucson, AZ) used in several experiments were $99.9999 \%$ pure.

Both samples of $\mathrm{La}_{2} \mathrm{~S}_{3}$ had oxygen contamination. A summary of the expected crystal systems in $\mathrm{La}_{2} \mathrm{~S}_{3}$ and related materials is shown in Table II [48, 49]. A Rietveld refinement of the $\mathrm{La}_{2} \mathrm{~S}_{3}$ powder supplied by Lorad chemicals showed that the primary phase (>96\%) was tetragonal $\mathrm{La}_{10} \mathrm{~S}_{14.55} \mathrm{O}_{0.45}$, essentially tetragonal $\beta-\mathrm{La}_{2} \mathrm{~S}_{3}$. The minor component was hexagonal $\mathrm{La}_{1.98} \mathrm{O}_{2.13} \mathrm{~S}_{0.84}$. By comparison, the $\mathrm{La}_{2} \mathrm{~S}_{3}$ supplied by American Elements is seen to consist of $100 \% \mathrm{La}_{10} \mathrm{~S}_{14.5} \mathrm{O}_{0.5}$, which is also the tetragonal $\beta-\mathrm{La}_{2} \mathrm{~S}_{3}$ form. It should also be noted that this material is somewhat less crystalline than the chemical from Lorad, evidenced by the lower peak intensities for the same count rate. The two chemical patterns for the majority phases (tetragonal) appeared to overlap, but are slightly shifted on the $2 \theta$-axis from one another and this is attributed to a slight chemical difference (O-content) between the chemicals. 


\subsection{Glass ceramic synthesis}

\subsubsection{Equipment and procedures}

The reactants, either as sulfides or elements, were weighed out on an analytical balance within the glovebox with a target total mass of $~ 5-10 \mathrm{~g}$, and then transferred into a mortar and pestle for homogenization. All samples with $\mathrm{La}_{2} \mathrm{~S}_{3}$ were added to a glassy carbon crucible with a tapered wall (Sigradur® HTW, Germany) and then a glassy carbon lid was placed on top, as had been suggested from previous studies of glasses containing $\mathrm{La}_{2} \mathrm{~S}_{3}$ [43]. Then the raw precursors or the loaded glassy carbon crucible were place into a fused quartz tube, a fused quartz end cap was placed inside the ampoule, and the assembly was connected to a vacuum system without the contents being exposed to air. After being evacuated to $\sim 10^{-4} \mathrm{~Pa}$, each ampoule was sealed with a torch.

This sealed ampoule was instrumented with five Type-K thermocouples (OMEGA Engineering, Inc., Stamford, CN) spanning the evacuated region and inserted into either a top loading furnace with $\mathrm{MoSi}_{2}$ heating elements and a mullite liner (for all samples containing $\mathrm{La}_{2} \mathrm{~S}_{3}$ ) or a rocking furnace (for all other samples) (Deltech, Inc., Denver, CO). Each sample was heated at a rate of $3{ }^{\circ} \mathrm{C} \min ^{-1}$ to a dwell temperature for $\sim 24$ hours, at which point it was either: (1) furnace cooled (denoted as “f”), (2) pulled out and air quenched (denoted as “a”), (3) pulled out and water quenched (denoted as "w"), or (4) ramped down to $800{ }^{\circ} \mathrm{C}$ and water quenched (denoted as "wc"). Cooled samples were mounted in resin and cut either with a diamond blade (Buehler, Lake Bluff, IL) or a diamond wire saw (CT400, Diamond Wire Technology, LLC, Colorado Springs, CO) and polished for further analyses. 


\subsection{2 $\mathrm{Ga}_{2} \mathrm{~S}_{3}-\mathrm{La} \mathrm{a}_{2} \mathrm{~S}_{3}$ system}

Three types of GLS compositions were investigated: (1) Ga-La-S alone, with different values for $R=\mathrm{Ga} /(\mathrm{Ga}+\mathrm{La}$ ) (by mole), (2) Ga-La-S with $\mathrm{Ca}$, and (3) Ga-La-S with Zn. The rationale was to target crystalline phases such as $\mathrm{La}_{3.33} \mathrm{Ga}_{6} \mathrm{~S}_{14}$ that also has an oxygen-containing variant $\mathrm{La}_{3.33} \mathrm{Ga}_{6} \mathrm{~S}_{12} \mathrm{O}_{2}$ for (1), $\mathrm{CaLa}_{2} \mathrm{~S}_{4}$ [50] for (2), and $\mathrm{ZnGa}_{2} \mathrm{~S}_{4}$ [51] for (3).

The $R=\mathrm{Ga} /(\mathrm{Ga}+\mathrm{La})$ between 0.5 and 0.8 reputedly forms glass [29]. In attempting to make a glass ceramic with high $\mathrm{La}_{2} \mathrm{~S}_{3}$ content, high strength, and the precipitation of at least a small fraction of the $\mathrm{CaLa}_{2} \mathrm{~S}_{4}$ phase, $R=0.72$ was chosen first, with an addition of $10 \mathrm{~mol} \% \mathrm{CaS}$. This composition was melted at $1200{ }^{\circ} \mathrm{C}$ and allowed to furnace cool (GaLS72-10Ca-f), air quench (GaLS72-10Ca-a), water quench (GaLS72-10Ca-w), and water quench after cooling to $800{ }^{\circ} \mathrm{C}$ (GaLS72-10Ca-cw). These processes were used to assess the importance of the quench rate. The cooling rate for air-quenching of ingots produced from the normal mass of precursor was estimated at $50-100{ }^{\circ} \mathrm{C} \min ^{-1}$ but not congruent throughout the material due to heat transfer limitations. The cooling rate for water-quenching of ingots was estimated to be $6000{ }^{\circ} \mathrm{C} \mathrm{min}^{-1}$ $\left(\sim 500{ }^{\circ} \mathrm{C} \mathrm{s}^{-1}\right)$ but may also be highly non-uniform. To evaluate the effect of $\mathrm{CaS}$ and $\mathrm{ZnS}$ additions, comparable $R=0.72$ compositions, one without CaS (GaLS72-a) and one substituting $10 \mathrm{~mol} \% \mathrm{ZnS}$ (GaLS72-10Zn-a), were produced and quenched in air. As research progressed, it became apparent that air quenching failed to produce a single-phase glass, so the amount of $\mathrm{La}_{2} \mathrm{~S}_{3}$ was reduced, and $\mathrm{Ga}: \mathrm{La}$ was adjusted. The $R=0.70$ system was investigated using a furnace cool (GaLS70-f) and an air quench (GaLS70-a). Finally, the $R=0.65$ system was produced with $20 \mathrm{~mol} \% \mathrm{CaS}$ and different quenches were investigated including a furnace cool (GLS62-20Ca-f; $1215{ }^{\circ} \mathrm{C}$ ), an air quench (GLS62-20Ca-a; $1300{ }^{\circ} \mathrm{C}$ ), and a water quench (GLS62-20Ca-w; $1200{ }^{\circ} \mathrm{C}$ ). The significance of the different maximum melting temperatures is 
discussed below. A summary of the sample compositions and synthesis methods for the $\mathrm{Ga}_{2} \mathrm{~S}_{3^{-}}$ $\mathrm{La}_{2} \mathrm{~S}_{3}$ systems is shown in Table III.

\subsubsection{Remelting of glass powders}

Two of the glasses obtained from the above procedure (GaLS72-10Ca-w and GaLS6520Ca-w) were ground and placed into alumina differential scanning calorimetry (DSC) pans. Approximately $30-40 \mathrm{mg}$ of these glass powders were then heated at $20{ }^{\circ} \mathrm{C} \mathrm{min}^{-1}$ up to 900 , 1000,1250 , or $1300{ }^{\circ} \mathrm{C}$ (samples had been originally processed $\sim 1200{ }^{\circ} \mathrm{C}$ ) in an argon cover gas. The samples were then allowed to cool in the DSC furnace at a cooling rate of $\sim 20{ }^{\circ} \mathrm{C} \min ^{-1}$. Note that this is somewhat slower than the nominal cooling rate of the air quench of ingots produced from the normal mass of precursor. The alumina DSC crucibles heated to various temperatures and still containing the specimens were then cross-sectioned and investigated using optical and electron microscopies.

\subsubsection{GeS $-\mathrm{La}_{2} \mathrm{~S}_{3}$ system}

The Ge-La-S [37, 43] system was investigated due to the potential to access a two-phase region where two La-Ga-S crystalline phases were stable, and above which the glass was stable, in the region around $55 \mathrm{GeS}_{2}-45 \mathrm{La}_{2} \mathrm{~S}_{3}$. Two experiments were performed with the $55 \mathrm{GeS}_{2^{-}}$ 45 $\mathrm{La}_{2} \mathrm{~S}_{3}$ composition. Both experiments were performed in glassy carbon crucibles inside evacuated silica tubes, and both were air quenched. The first (GeLS-1100-a) was melted at 1100 ${ }^{\circ} \mathrm{C}$, slightly above the liquidus of $1050{ }^{\circ} \mathrm{C}$ as reported by the phase diagram [43]. The other experiment was conducted in the same furnace except at a lower temperature of $900{ }^{\circ} \mathrm{C}(\mathrm{GeLS}$ 900-a). A summary of the sample compositions and synthesis methods for the $\mathrm{GeS}_{2}$ systems is shown in Table III. 


\subsection{4 $\mathrm{GeS}_{2}-\mathrm{Ga}_{2} \mathrm{~S}_{3}-\mathrm{CdS}$ system}

A third system, Ge-Ga-Cd-S [38, 39, 52-54], was identified which appeared promising for making glasses with good infrared transmission. First, a direct comparison was made producing two glasses with the same composition but one produced using sulfide precursors $\left(\mathrm{CdS}, \mathrm{Ga}_{2} \mathrm{~S}_{3}, \mathrm{GeS}_{2}\right)$ and the other produced using elemental precursors $(\mathrm{Cd}, \mathrm{Ge}, \mathrm{Ga}, \mathrm{S})$, to investigate the effect of the source material. This kind of experiment was not considered with the systems containing $\mathrm{La}_{2} \mathrm{~S}_{3}$ since La metal is pyrophoric and there were safety concerns about its use. Both the sample from sulfides (GGLS-15CdS-s-w) and the sample from elements (GGLS-15CdS-e-w) were melted at the same temperature of $1050{ }^{\circ} \mathrm{C}$ and water quenched. Next, a more $\mathrm{GeS}_{2}$-rich composition was made, and elements were used for two iterations to test the effect of the quench, with one sample being water quenched (GGLS-5CdS-e-w) and one being air quenched (GGLS-5CdS-e-a).

\subsection{Material characterization}

\subsubsection{Visual inspection and microscopy}

Due to the scoping nature of this study, immediate visual assessment was an important first step in assessing the glassy versus crystalline nature of the ceramic. In some cases, samples were cross-sectioned and examined with optical microscopy. For select samples, scanning electron microscopy (SEM) was performed with a JEOL JSM-7001F (JEOL Ltd., Tokyo, Japan) using the backscattered electron (BSE) detector and energy dispersive spectroscopy (EDS) was performed with an EDAX Apollo XL $30 \mathrm{~mm}^{2}$ Si drift detector (AMETEK, Berwyn, PA). A summary of the visual observations, microstructure, and characterization performed on each sample is shown in Table IV. 


\subsubsection{X-ray diffraction}

X-ray diffraction (XRD) was performed on all samples with a Bruker® D8 Advance (Bruker AXS Inc., Madison, WI) XRD with $\mathrm{Cu} \mathrm{K}_{\alpha}$ emission. The detector used was a LynxEye $^{\mathrm{TM}}$ position-sensitive detector with a collection window of $3^{\circ} 2 \theta$. Scan parameters were $5-70^{\circ} 2 \theta$ with a step of $0.015^{\circ} 2 \theta$ and a 0.3 -s dwell at each step. For studying the raw materials, small quantities were mixed with ethanol and spread onto a zero-background silicon holder, with the ethanol being dried off prior to analysis. Heat-treated specimens were either run as cut and polished ingots or as powders and mounted in a way to increase the quantity of sample for analysis.

Bruker AXS DIFFRAC ${ }^{\text {plus }}$ EVA (v14) and Topas (v4.2) were used for phase identification and Rietveld pattern refinements, respectively. The Rietveld analysis for phase quantification was approximate and often resulted in unfit peaks (phases not in the database). The SEM-EDS data was used in conjunction with the XRD data to allow for phase identification.

\subsubsection{Thermal analysis}

For select samples that were completely glassy upon quenching, thermo-gravimetric analysis (TGA) and DSC were used to determine melting and crystallization properties using a TA Instruments SDT Q-600 (New Castle, DE). Approximately $30 \mathrm{mg}$ of powdered glass was placed into a $90-\mu \mathrm{L}$ alumina crucible for each run.

Each sample was first set to equilibrate at $85^{\circ} \mathrm{C}$ and then was heated with argon cover gas at constant heating rates of $1,2,5,10$, or $20 \mathrm{~K} \mathrm{~min}^{-1}$ to $900{ }^{\circ} \mathrm{C}$. The heat flow (W/g) for each run was then analyzed to determine temperatures for glass transition $\left(T_{\mathrm{g}}\right)$, onset of crystallization $\left(T_{\mathrm{x}}\right)$, peak crystallization temperature $\left(T_{\mathrm{c}}\right)$, and melting temperature $\left(T_{\mathrm{m}}\right)$. These values for different heating rates [55] allowed for the calculation of the glass formation constant 
also known as the Hruby criterion [56, 57]), as defined in Equation (1). Oftentimes, data is not available for $T_{\mathrm{x}}$ and $T_{\mathrm{m}}$, so sometimes only $T_{\mathrm{c}}-T_{\mathrm{g}}$ is compared. The larger this number, the more readily the system forms a glass and the larger the acceptable processing window for cooling.

$$
K_{g l}=\left(T_{x}-T_{g}\right) /\left(T_{m}-T_{c}\right)(1)
$$

Next, approximately $30 \mathrm{mg}$ of quenched glass was equilibrated at $85{ }^{\circ} \mathrm{C}$ and then heated with argon cover gas at $20 \mathrm{~K} / \mathrm{min}$ to various temperatures $560-600{ }^{\circ} \mathrm{C}$ (i.e., a temperature slightly greater than $T_{\mathrm{g}}$ of the sample). Then, a new sample of quenched glass was used for each temperature so as to precisely control the heating history. Each sample was then held at the target temperature for 30 minutes and then ramped at $20 \mathrm{~K} / \mathrm{min}$ to $900{ }^{\circ} \mathrm{C}$ and the exothermic heat flow giving $T_{\mathrm{c}}$ was recorded. This run was repeated multiple times, with new samples each time, where the hold temperature was increased by $5{ }^{\circ} \mathrm{C}$ for each run until reaching a hold temperature of $600{ }^{\circ} \mathrm{C}$. These values allowed for calculation of the nucleation temperature dependence of the sample using the Marotta method [58, 59]. Here, the nucleation curve was created by plotting $\ln \left(I_{0}\right)=\frac{E_{c}}{R}\left(\frac{1}{T_{p}}-\frac{1}{T_{p}^{0}}\right)+$ constant

where $T_{p}^{0}$ was the temperature at the peak (i.e., $T_{\mathrm{c}}$ ) measured with no isothermal hold, $T_{p}$ was the peak measured with an isothermal hold at temperature $T, I_{0}$ was the steady state nucleation rate, $E_{\mathrm{c}}$ was the activation energy for crystallization, and $R$ was the gas constant. Due to the constant term in this equation, the quantitative nucleation rate could not be determined by this method, but the temperature dependence was measured.

Finally, new samples were again equilibrated at $85^{\circ} \mathrm{C}$ and then heated in argon cover gas at $20 \mathrm{~K} / \mathrm{min}$ to $590{ }^{\circ} \mathrm{C}$ (i.e., a temperature near the suspected growth rate maxima) and then held 
at that temperature for 5 minutes. The temperature was then reduced to $500{ }^{\circ} \mathrm{C}$ (i.e., below $T_{\mathrm{g}}$ ) to freeze in the crystals, and then increased to $900{ }^{\circ} \mathrm{C}$ at a heating rate of $20 \mathrm{~K} / \mathrm{min}$. The crystallization peak area (heat of reaction) was measured for each run for the calculation of crystal growth temperature dependence using the Ray method [58, 60]. The quantity plotted versus temperature was the change in exothermic area under the crystallization peak, $\Delta A=A_{0}-A_{\mathrm{T}}$, where $A_{0}$ was the area in the absence of a 5-min hold at any temperature, $T$, and $A_{\mathrm{T}}$ was the area measured for a hold at $T$.

\subsubsection{Infrared transmission}

Infrared transmission spectra were collected for larger polished discs using a Fourier transform infrared (FTIR) spectrometer (Nicolet 6700, Thermo Fisher Scientific, Waltham, MA). A sample of GLS glass obtained from Crystran Ltd. (UK) and GLS glass samples obtained from Southampton University that had been previously measured for refractive index [61] were measured with FTIR. Infrared transmission spectra were also collected from small pieces of glass using an infrared microscope integrated with a Bruker IFS66 FTIR Spectrometer. Glass pieces were mounted in resin and polished on both sides for transmission measurements.

\subsubsection{Mechanical hardness}

For hardness measurements using micro- and nano-indentation, samples were mounted to a steel block prior to placement on the stage platform. Indents were made using a nano-Vickers diamond indenter attached to the indenter module. A region to be tested was then identified and all indents within that region were made. To prevent interference from other regions, all indents for a specific region were made $\sim 10-\mu \mathrm{m}$ apart. Hardness values were obtained from the loadversus-depth measurements. The micro- and nano-indentation hardness values reported are an average of multiple data points. For reference, samples of CVD ZnS (Vitron Spezialwerkstoffe 
GmbH, Germany), multispectral ZnS (Vitron), and GLS glass (Crystran Ltd., UK) were measured using the same apparatus.

\section{Results}

A summary of the compositions, quench conditions, and raw materials used for each sample are shown in Table III for $\mathrm{Ga}_{2} \mathrm{~S}_{3}-\mathrm{La}_{2} \mathrm{~S}_{3}$ systems and Table IV for $\mathrm{GeS}_{2}$ systems. Additionally, characterization performed for each experiment, visual appearance, and general microstructure are noted. In general, water quenching was the only way to obtain crystal-free glasses in the systems investigated. A matrix of the phases identified by XRD is shown in Table V, along with the fraction of each crystalline phase identified and the phase number in the International Crystal Structure Database (ICSD). A quantification of residual glass was not made, and, based on SEM observations, a significant fraction of the crystallized materials had remaining glassy material. Below, specific results on the two systems are given.

\section{1 $\mathrm{Ga}_{2} \mathrm{~S}_{3}-\mathrm{La}_{2} \mathrm{~S}_{3}$ systems}

\subsubsection{Visual observations, microstructure, and crystallization}

Note that the following series of samples should be compared with one another to see the effects of composition and/or processing:

\subsubsection{GaLS72-10Ca series}

The GaLS72-10Ca series provided information on the effect of quench technique on the $\mathrm{Ga} /(\mathrm{Ga}+\mathrm{La})=0.72$ system with 10 mole $\% \mathrm{CaS}$. The furnace-cooled sample (GaLS72-10Ca-f) appeared very crystallized, and was shown by XRD to contain mostly $\mathrm{CaGa}_{2} \mathrm{~S}_{4}$ with some $\mathrm{Ga}_{2} \mathrm{~S}_{3}$ and $\mathrm{La}_{3} \mathrm{~S}_{4}$, with possible traces of oxides, i.e., $\mathrm{La}_{3.33} \mathrm{Ga}_{6} \mathrm{~S}_{12} \mathrm{O}_{12}$ and $\mathrm{Ga}_{2} \mathrm{O}_{3}$. The air quench sample (GaLS72-10Ca-a) appeared somewhat crystallized on the top and glassy elsewhere but 
highly fractured, and was shown by XRD to contain mostly $\mathrm{Ga}_{2} \mathrm{~S}_{3}$ with oxides $\mathrm{CaO}$ and $\mathrm{Ca}_{3} \mathrm{Ga}_{4} \mathrm{O}_{7}$ with traces of $\mathrm{LaS}_{1.96}$. Microstructures of these samples are shown in Figure 3c (GaLS72-10Ca-f) and Figure 3d (GaLS72-10Ca-a). The GaLS72-10Ca-f sample had a large fraction of crystallization, some of which may be unreacted material, while GaLS72-10Ca-a appeared to be largely phase-separated.

In GaLS72-10Ca-f, SEM-EDS spectra confirm the presence of a needle-like La-S phase (bright areas), small spots of Ga-S (dark areas), a major phase of Ca-Ga-S (grey areas), and an interface phase of Ga-La-O-S on the border of the La-S crystals (Figure 4a). The GaLS7210Ca-a sample was more difficult to assess with EDS, but three phases were evident by BSE contrast, and seemed to consist of Ga-S (black, possibly crystalline), Ca-La-rich glass (white), and Ga-rich glass (grey). The GaLS72-10Ca-cw sample, which was cooled to $800{ }^{\circ} \mathrm{C}$ prior to air quenching, appeared visually similar to GaLS72-10Ca-a but was not analyzed for crystallization. The GaLS72-10Ca-w was completely glassy as confirmed by XRD. In the case of the water quenched sample, the silica ampoule shattered when placed in the water, and water entered inside the ampoule, cracking the glassy carbon lid of the crucible and coming into direct contact with the glass, resulting in a fractured amorphous sample.

\subsubsection{GaLS72-10Ca-a versus GaLS72-a}

The comparison of GaLS72-10Ca-a versus GaLS72-a demonstrated the effect of composition (addition of 10 mole $\% \mathrm{CaS}$ ) on the $\mathrm{Ga} /(\mathrm{Ga}+\mathrm{La})=0.72$ for air-quenched glass. GaLS72-a was just the base GLS glass with the ratio as mentioned, while, for GaLS72-10Ca-a, the ratio was conserved but $\mathrm{CaS}$ was added. The sample without $\mathrm{CaS}$ actually appeared more crystallized upon quenching, being wholly opaque and cracked. The inside of the GaLS72-a ingot appeared visibly crystallized and was approximately the color of the top surface of the 
GaLS72-10Ca-a sample. XRD indicated that, without CaS additions, crystalline phases were mostly $\mathrm{Ga}_{2} \mathrm{~S}_{3}$ with some $\mathrm{GaLa}_{3} \mathrm{OS}_{5}$ and possibly some $\mathrm{La}$ and $\mathrm{La}_{2} \mathrm{O}_{3}$. As previously stated, with $10 \mathrm{CaS}$, phases were mostly $\mathrm{Ga}_{2} \mathrm{~S}_{3}$ with oxides $\mathrm{CaO}$ and $\mathrm{Ca}_{3} \mathrm{Ga}_{4} \mathrm{O}_{7}$ with traces of $\mathrm{LaS}_{1.96}$. Figure 3b (with $10 \mathrm{CaS}$ ) and Figure 3d (no $\mathrm{CaS}$ ) show the microstructures of these samples. Both samples appear to be phase-separated, with the scale of the phase separation being smaller for the sample with $\mathrm{CaS}$.

\subsubsection{GaLS72-10Ca-a versus GaLS72-10Zn-a}

The comparison of GaLS72-10Ca-a versus GaLS72-10Zn-a demonstrates effect of composition, 10 mole\% $\mathrm{ZnS}$ versus 10 mole\% $\mathrm{CaS}$, for air-quenched samples. Visually, the $\mathrm{ZnS}$ sample looked similar to the CaS sample. Microstructurally, however, the glass with $\mathrm{ZnS}$ (Figure 3a) was much more crystallized that that with CaS (Figure 3d). XRD showed phases of $\mathrm{Ga}_{2} \mathrm{O}_{12} \mathrm{~S}_{3}, \mathrm{Zn}_{3} \mathrm{~S}_{2} \mathrm{O}_{9}, \mathrm{ZnGa}_{2} \mathrm{~S}_{4}, \mathrm{ZnLa}_{2} \mathrm{Ga}_{2} \mathrm{OS}_{6}$ and possibly some $\mathrm{La}_{2} \mathrm{O}_{2} \mathrm{~S}_{2}$ for the $\mathrm{ZnS}$-containing glass. While GaLS72-10Zn-a was highly crystallized upon air quenching, GaLS72-10Ca-a appeared more phase-separated. Desiring control of the microstructure by subsequent heat treatments, the $\mathrm{ZnS}$-containing compositions were abandoned in favor of the CaS-containing ones following this observation. The SEM-EDS analysis of the Zn-glass showed La-S lenticular crystals (white), Ga-La-S glass (grey), and Zn-Ga-S crystals (grey), and possibly a La-O-S interface phase around the $\mathrm{Zn}-\mathrm{Ga}-\mathrm{S}$ crystals (Figure $\mathbf{4 b}$ ). Note the phase assemblage of the GaLS72-10Zn-a (Figure 3a) is very similar to that of the GaLS72-10Ca-f (Figure 3c).

\subsubsection{GaLS72-a versus GaLS70-a}

The GaLS72-a versus GaLS70-a comparison demonstrates the effect of $R=\mathrm{Ga} /(\mathrm{Ga}+\mathrm{La})$ ratio on air-quenched sample. Both samples appeared opaque upon quenching. While the $R=0.70$ glass was supposedly closer to the commercial glass ratio, even the GaLS70-a 
composition did not form a glass readily with air quenching. At this point, it was suspected that the oxygen content and the $\mathrm{La}_{2} \mathrm{~S}_{3}$ source was a significant issue. The XRD results suggested that the $R=0.72$ glass contained crystals of $\mathrm{Ga}_{2} \mathrm{~S}_{3}$ (majority), $\mathrm{GaLa}_{3} \mathrm{OS}_{5}, \mathrm{La}$, and $\mathrm{La}_{2} \mathrm{O}_{3}$ while the $R=0.70$ had $\mathrm{Ga}_{2} \mathrm{~S}_{3}, \mathrm{~S}, \mathrm{LaGaS}_{3}$, and minor $\mathrm{La}_{2} \mathrm{~S}_{3}$. Microstructures show phase separation both the $R=0.72$ (Figure 3d) and the $R=0.70$ (not shown, but similar microstructure to Figure $\mathbf{3 b}$, $\mathbf{d}$, and e depending on location).

\subsubsection{GaLS70-f versus GaLS70-a}

The comparison of GaLS70-f versus GaLS70-a demonstrates the effect of quench method on $R=0.70$ composition, i.e., furnace slow cool (GaLS70-f) versus air quench (GaLS70-a). Qualitatively, these were very similar. The XRD results showed that GaLS70-a contained $\mathrm{Ga}_{2} \mathrm{~S}_{3}$, $\mathrm{S}, \mathrm{LaGaS}_{3}$, and minor $\mathrm{La}_{2} \mathrm{~S}_{3}$ whereas GaLS70-f showing more $\mathrm{S}$ and less $\mathrm{Ga}_{2} \mathrm{~S}_{3}$ and $\mathrm{LaGaS}_{3}$ and no $\mathrm{La}_{2} \mathrm{~S}_{3}$. Unlike the GaLS72-10Ca samples, where GaLS72-10Ca-f was substantially more crystallized than GaLS72-10Ca-a, the GaLS70 samples seemed quite similar for the furnace cool (Figure 3e) and air quench (not shown, see above).

\subsubsection{GaLS65-20Ca series}

The GaLS65-20Ca series demonstrated the effect of quench (furnace cool, air quench, water quench) on the $\mathrm{Ga} /(\mathrm{Ga}+\mathrm{La})=0.65$ system with 20 mole\% CaS. The GaLS65-20Ca-w sample was amorphous by XRD and the crystallinity was not determined for the other samples. When cross-sectioned, GaLS65-20Ca-a showed the presence of a fast-cooled outer "shell" and a slow-cooled inner "core." The SEM analysis showed evidence of phase separation in both regions, but with the outer region showing very fine structuring of the phase separation (Figure 3f) compared to the inner region (similar microstructure to Figure 3b). A distinct boundary 
between these regions was also observed. Note that GaLS65-20Ca-a was heated to $1300{ }^{\circ} \mathrm{C}$ before quenching, compared to the usual procedure at $1200{ }^{\circ} \mathrm{C}$ (see rationale below).

\subsubsection{Overview of comparisons}

To summarize, air-quenched samples, if they were not strongly crystallized (such as GaLS72-10Zn-a, Figure 3a), were always phase-separated. The only single-phase glasses produced were water quenched (GaLS72-10Ca-w and GaLS65-20Ca-w), and all glasses waterquenched from the melt temperature were single-phase and not phase-separated. Thus, it appears that there exists a strong driving force for phase-separation in this system. Despite this, there is no mention of this tendency in the literature, although it has been discussed that oxygen additions are needed for good glass-formation [30]. Note that for $R=0.70$ (less $\mathrm{Ga}$ ), $n=0.72$ (more $\mathrm{Ga}$ ), and $n=0.72$ (including $\mathrm{CaS}$ ), phase-separation was similar (see Figure 5a-c). Microstructures were very heterogeneous and multi-scale, and there appeared to be at least three phases, one spinodal, one Ga-rich, and one La-rich. However, details of the phase-separation appear different (see Figure 5d-g).

\subsubsection{Remelting of glass powders}

It was hypothesized that the phase-separation of the Ga-La-S glasses, and in some cases the crystallization, was due to inadequate mixing of the precursors at the melt temperature. For example, it has been shown previously for $\mathrm{GeS}_{2}$ that 192 hours is required to fully homogenize the melt such that the quenched glass showed identical micro-Raman signatures on a $10-\mu \mathrm{m}$ scale [62]. The single-phase glasses obtained in the current Ga-La-S study were water quenched (GaLS72-10Ca-w and GaLS65-20Ca-w) and this process resulted in very small fragments of homogenous glass. Heating of a small mass of this glass frit to $\geq 1250{ }^{\circ} \mathrm{C}$ in argon in DSC pans followed by cooling at $\sim 20{ }^{\circ} \mathrm{C} \mathrm{min}^{-1}$ resulted in solid pieces of glass without cracking (see 
Figure 6). It was hypothesized that this remelt of glass could be a means of producing larger specimens. When re-processed at $1100{ }^{\circ} \mathrm{C}$ and cooled, samples were not yet homogenous glasses, but appeared to be homogenous when processed above this temperature. The glass with more CaS (GaLS65-20Ca-w) still appeared by SEM to have fine-scale phase-separation when processed at $1250{ }^{\circ} \mathrm{C}$ (but homogenous at $1300{ }^{\circ} \mathrm{C}$ ) while the glass with less $\mathrm{CaS}$ (GaLS72$10 \mathrm{Ca}-w)$ was homogenous even at $1250{ }^{\circ} \mathrm{C}$.

Samples heated to $1100{ }^{\circ} \mathrm{C}$ were further investigated using SEM-EDS to determine the structures present just before forming a homogenous glass (see Figure 7). It was apparent that these two glasses had very different behavior when reheated and quenched. The glass with higher Ga and lower $\mathrm{Ca}(\mathrm{GaLS72}-10 \mathrm{Ca}-\mathrm{w})$ phase-separated, while the glass with lower Ga and higher Ca (GaLS65-20Ca-w) was crystallized. In GaLS65-20Ca-w, oxygen was concentrated in the crystalline phases Ga-La-O-S and La-O-S. Contact with the alumina crucible resulted in minor crystallization of La-Al-O (GaLS72-10Ca-w, $1250{ }^{\circ} \mathrm{C}$ ) and nucleation of La-S crystals (GaLS65-20Ca-w, $1250{ }^{\circ} \mathrm{C}$ ) or Ga-La-O crystals (GaLS65-20Ca-w, $1300{ }^{\circ} \mathrm{C}$ ).

To test the hypothesis that a higher melting temperature was needed for homogenization, an ingot was made using the normal process but heated at $1300{ }^{\circ} \mathrm{C}$ and air quenched (GaLS6520Ca-a). The result appeared similar to other Ga-La-Ca-S samples in that it was opaque. This sample was cross-sectioned and analyzed with SEM-EDS. It was heterogeneous with a core and a shell phase of different optical appearance and microstructure where SEM showed that the shell consisted of small-scale phase-separation with some large voids and the core consisted of larger-scale phase-separation. Some crystals appeared similar to those observed in other samples. This test showed that a higher melting temperature did not promote the production of a single-phase glass upon air quenching. Thus it seems that melt homogeneity is not a factor in the 
phase-separation and crystallization of this system. The fact that the DSC pan experiments showed no phase-separation or crystallization upon cooling as long as they were heated above $1250{ }^{\circ} \mathrm{C}$, suggests that the lower thermal mass may have allowed for the formation of a glass while cooling at a rate slower than air quenching the ingot. Another possibility is that the glasses, once powdered for the DSC, picked up some oxygen, which then facilitated glass formation as has been suggested previously [30].

\subsubsection{Thermal analysis}

Thermal analysis was used to help determine the optimum processing conditions for glass ceramics in the Ga-La-(Ca)-S system. Two glasses were chosen, both without crystals after water quenching (GaLS72-10Ca-w and GaLS65-20Ca-w). For the former glass with less Ca, $T_{\mathrm{g}}$ varied in each case from $529.6-555.8^{\circ} \mathrm{C}, T_{\mathrm{x}}$ varied $600.2-638.8^{\circ} \mathrm{C}, T_{\mathrm{c}}$ varied $604.5-646.2{ }^{\circ} \mathrm{C}$, and $T_{\mathrm{m}}$ varied $866.1-868.7^{\circ} \mathrm{C}$, with the lower and higher temperatures being determined from data collected at a $1{ }^{\circ} \mathrm{C} \min ^{-1}$ and $20{ }^{\circ} \mathrm{C} \min ^{-1}$ heating rate, respectively. This results in a $K_{\mathrm{gl}}$ of $0.270-0.373$. In order to compare to other systems where only $T_{\mathrm{c}}$ and $T_{\mathrm{g}}$ are reported, $T_{\mathrm{c}}-T_{\mathrm{g}}$ was calculated, giving $75-90{ }^{\circ} \mathrm{C}$ for the GaLS72-10Ca-w glass, compared to $49{ }^{\circ} \mathrm{C}$ for $\mathrm{BaAl}_{4} \mathrm{O}_{7}$ [13] and $218{ }^{\circ} \mathrm{C}$ for cordierite (sample 1 in [15]). It can thus be seen that the Ga-La-Ca-S studied is not a particularly good glass-former, but is better than $\mathrm{BaAl}_{4} \mathrm{O}_{7}$, which only forms a glass when a levitation-laser method is used giving very high quench rates [13].

Nucleation and growth curves were computed for GaLS72-10Ca-w and GaLS65-20Ca-w homogenous glasses as described previously. Performing these analyses, it was observed that when adding $\mathrm{CaS}$ and reducing $\mathrm{Ga} /(\mathrm{Ga}+\mathrm{La})$ (GaLS65-20Ca-w compared to GaLS72-10Ca-w), the peak of the nucleation curve increases from 590 to $610{ }^{\circ} \mathrm{C}$ and the flat part of the growth curve increases from 620 to $650{ }^{\circ} \mathrm{C}$ (see Figure 8). 


\section{2 $\mathrm{GeS}_{2}$ systems}

\subsubsection{GeS $-\mathrm{La}_{2} \mathrm{~S}_{3}$ system}

Neither of the experiments made in the $\mathrm{GeS}_{2}-\mathrm{La}_{2} \mathrm{~S}_{3}$ system resulted in a successful glass. The first experiment, GeLS-1100-a, produced volatile species that escaped the crucible and condensed on the cooler portion of the sealed ampoule, leaving a metallic porous ingot. The XRD results showed that the ingot consisted of $\mathrm{Ge}_{3.33} \mathrm{La}_{6} \mathrm{~S}_{14}, \mathrm{La}_{10} \mathrm{~S}_{14.5} \mathrm{O}_{0.5}$, and $\mathrm{S}$ with a small amount of Ge, while the ampoule wall was mostly GeS with a small amount of Ge (see Table V). The hexagonal $P 6_{3}$ Ge-La-S phase is mentioned in Michelet et al [46] as $\mathrm{RE}_{6} \mathrm{Ge}_{2.5} \mathrm{~S}_{14}$ or $\mathrm{RE}_{6} \mathrm{Ge}_{3} \mathrm{~S}_{14}$, depending on the valence assumed for $\mathrm{Ge}$, but it is not mentioned for $\mathrm{RE}=\mathrm{La}$ and it is not clear how this would fit into the phase diagram shown in Figure 2.

The second experiment at lower temperature (GeLS-900-a) produced no volatile components condensed on the ampoule wall. However, it appeared that the $\mathrm{GeS}_{2}$ precursor decomposed and left a sulfur-rich area on the top surface. Additionally, the ingot was porous and appeared heterogeneous. The XRD results of this sample suggested high levels of crystalline sulfur and germanium, with traces of $\mathrm{La}_{2} \mathrm{~S}_{3}$ and $\mathrm{La}_{2} \mathrm{GeS}_{5}$, and many unfit peaks which could not be indexed from phases in the database (see Table V). The Ge-La-S phase produced was the "2-1-5, La-Ge-S" monoclinic $P 112_{1} / a$, as reported by Michelet et al [46]. To further investigate the nature of this sample, SEM-EDS was performed, confirming that microstructure was indeed very porous with what appeared to be a homogenous phase (which could be Ge-La-S glass) with Ge (or possible Ge-S) inclusions. Nano-indentation hardness data (see Section 4.4) provide evidence that this second phase is Ge.

Previous studies of glass formation in this system focused on $60 \mathrm{GeS}_{2}-40 \mathrm{La}_{2} \mathrm{~S}_{3}$ and 92.5GeS $\mathrm{G}_{2}-7.5 \mathrm{La}_{2} \mathrm{~S}_{3}$ [43]. Transmission electron microscopy showed that the $60 \mathrm{GeS}_{2}-40 \mathrm{La}_{2} \mathrm{~S}_{3}$ 
composition was a homogenous glass, while the $92.5 \mathrm{GeS}_{2}-7.5 \mathrm{La}_{2} \mathrm{~S}_{3}$ composition was phaseseparated. Upon heat treatment of the $60 \mathrm{GeS}_{2}-40 \mathrm{La}_{2} \mathrm{~S}_{3}$ glass, which consisted of a ramp $10{ }^{\circ} \mathrm{C}$ $\min ^{-1}$ in $\mathrm{He}$ to $850{ }^{\circ} \mathrm{C}$ with 1 -min hold, $\beta$-La $\mathrm{S}_{3}$ crystallized in the bulk and $\mathrm{GeS}_{2}$ remained amorphous. By contrast, the $92.5 \mathrm{GeS}_{2}-7.5 \mathrm{La}_{2} \mathrm{~S}_{3}$ composition was heated at $10{ }^{\circ} \mathrm{C} \mathrm{min}{ }^{-1}$ in $\mathrm{He}$ to $700{ }^{\circ} \mathrm{C}$ with 6-min hold and resulted in the formation of rhombohedral $\mathrm{La}_{4} \mathrm{Ge}_{3} \mathrm{~S}_{12}$ crystals [43].

The $\mathrm{La}_{4} \mathrm{Ge}_{3} \mathrm{~S}_{12}$ phase, described by Michelet et al [46], is one of the end-members of the twophase region. The other is the monoclinic $\mathrm{La}_{2} \mathrm{GeS}_{5}$, which is described as being unstable at $<600$ ${ }^{\circ} \mathrm{C}$ but decomposes into $\mathrm{La}_{2} \mathrm{~S}_{3}$ (solid) and $\mathrm{GeS}_{2}$ (vapor) unless there is a sufficient overpressure of $\mathrm{GeS}_{2}$ [46]. In the two attempts at synthesis discussed here, a very small amount of the monoclinic phase or hexagonal phase was produced. Clearly there is more work to be done to establish appropriate synthesis conditions for the Ge-La-S phases.

\subsection{2 $\mathrm{GeS}_{2}-\mathrm{Ga} \mathrm{a}_{2} \mathrm{~S}_{3}-\mathrm{CdS}$ system}

The first study here was to test the effect of precursor chemicals on the melt outcome. The sample made from elements (GGLS-15CdS-e-w) made transparent amber glass with a few red inclusions while the sample made from sulfides (GGLS-15CdS-s-w) made a friable metallic lump (see Figure 9). The XRD analysis of these samples showed the glass to be amorphous and the metallic powder to be composed of $\mathrm{Cd}-\mathrm{Ga}-\mathrm{S}, \mathrm{CdGa}_{2} \mathrm{~S}_{4}, \mathrm{GaS}$, and a GeGa alloy (see Table V). The reason for this dramatic difference was not fully determined. It could be due to the slightly higher purity of the elemental starting materials, but more likely was due to the temperature fluxing from the melting of elemental sulfur and the subsequent sequence of reaction products.

The second study was to test the effect of the quench when only elemental precursors (preferred, as above) were used. A slightly different composition, richer in $\mathrm{GeS}_{2}$, was used to 
attempt to get a glass with a larger predicted value of $T_{\mathrm{c}}-T_{\mathrm{g}}$ [39]. As shown in Figure 9, the water quenched sample, GGLS-5CdS-e-w, made transparent reddish glass and the air quenched sample, GGLS-5CdS-e-a, made a metallic ingot. The XRD results showed the glass to be amorphous and the metallic ingot to contain $\mathrm{GeS}_{2}$, orthorhombic space group Fdd2 (see Table V and Figure 10). It appears, then, that water quenching of glasses from elemental precursors is necessary to produce a homogenous glass in this Ge-Ga-Cd-S system.

\subsection{Infrared transmission}

The measured transmittance of GLS glasses whose refractive indices were previously reported [61] were compared to the commercial Crystran glass in Figure 11. It is apparent that the Crystran glass contains a large absorption $\sim 8.5 \mu \mathrm{m}$ consistent with other glasses known to have comparatively high or comparatively low levels of oxygen.

Transmission spectra were taken through a microscope for glassy specimens GaLS6520Ca-w (Ga-La-Ca-S), GGLS-15CdS-e-w (Ge-Ga-Cd-S), and GGLS-5CdS-e-w (Ge-Ga-Cd-S) and the results are shown in Figure 12. The Ge-Ga-Cd-S glasses appeared transparent to at least $11 \mu \mathrm{m}$, while the Ge-La-Ca-S glass appeared quite opaque and may have a problem associated with the measurement such as internal fracturing from stress promoting scattering losses. The strong absorption bands in the Ge-Ga-Cd-S glasses at $\sim 4 \mu \mathrm{m}$ were not identified.

\subsection{Mechanical hardness}

The results from mechanical hardness testing is shown in Table VI. The hardness data for CVD ZnS produced by this technique $(1.75 \mathrm{GPa})$ are in-line with literature data for $\sim 5-\mu \mathrm{m}$ grain size material [63]. One phase-separated glass (Ga-La-S with no Ca, GaLS72-a) was investigated with nano-indentation (average of 8 points) and found to have a homogenous distribution of hardness values with a slightly higher standard deviation than the other glasses. 
Note, however, that it was the hardest glass measured at $>4 \mathrm{GPa}$. The Ga-La-Zn-S glass ceramic (GaLS72-10Zn-a) was measured, and two mechanically different phases were found, with averages of $\sim 2.8 \mathrm{GPa}$ (average of 4 points) and $\sim 5.6 \mathrm{GPa}$ (average of 3 points). In comparing the microscopy accompanying the nano-indentation with the SEM-EDS, it appeared that the softer phase was the $\mathrm{ZnGa}_{2} \mathrm{~S}_{4}$ crystals and the harder phase was the Ga-La-S glass.

In the Ge-La-S sample (GeLS-900-a), two phases were evident from SEM-EDS and these phases were probed separately using nano-indentation. Nano-indentation data were averages of 3 points (phase 1) or 4 points (phase 2). A very hard phase was evident (13.3 GPa) which was tentatively identified as Ge (as per EDS analysis) as it is reported to have Vickers' hardness of 913 GPa [64].

Several observations can be made with respect to this data. Note that all glasses and glass ceramics produced in this study were harder than CVD ZnS, the baseline LWIR ceramic. First, the phase-separated glass, GaLS72-a, was the hardest of the glasses, including the other Ga-La-S glass, GaLS65-20Ca-w, which was not phase-separated and contained similar amounts of $\mathrm{La}_{2} \mathrm{~S}_{3}$, but also included CaS. Second, what appears to be the glassy phase in the Ga-La-Zn-S sample (GaLS72-10Zn-a) is harder than the major crystalline phase, which does not contain $\mathrm{La}_{2} \mathrm{~S}_{3}$. Additionally, what appears to be the glass phase (phase 2, GaLS72-10Zn-a) is harder yet than even the phase-separated glass. If the identification of the phases is correct, this implies that a glass with crystalline microstructure may, in fact, be quite hard overall, and that the glassy phase might not necessarily be the softer phase. However, it is apparent in the Ge-La-S sample that the glass phase (phase 1, GeLS-900-a) is the softer one, with Ge being quite hard as is expected of a material with the diamond structure. 


\section{Discussion}

Two very different glass-forming systems were explored as part of this scoping study. The $\mathrm{Ga}_{2} \mathrm{~S}_{3}-\mathrm{La}_{2} \mathrm{~S}_{3}$ system was a moderately good glass-former, with $T_{\mathrm{c}}-T_{\mathrm{g}}$ of $75-90{ }^{\circ} \mathrm{C}$ (for the GaLS72-10Ca-w glass). The $\mathrm{GeS}_{2}-\mathrm{Ga}_{2} \mathrm{~S}_{3}-\mathrm{CdS}$ system showed more effective glass formation, with a value of $T_{\mathrm{c}}-T_{\mathrm{g}}=125-159{ }^{\circ} \mathrm{C}$ (for GGLS-15CdS-e-w and GGLS-5CdS-e-w, respectively, based on thermal data from [39]). The larger value of $T_{\mathrm{c}}-T_{\mathrm{g}}$ gives a much more forgiving processing envelope, allowing a slower quench while still achieving glass formation without crystallization. This being said, there are several ways to consider making a LWIR-transmitting glass ceramic. All of these should be thoroughly explored and will affect the final glass-forming system used.

Systems with a small value of $T_{\mathrm{c}}-T_{\mathrm{g}}$ will only form glasses when produced by very high quench rates. A glass powder could be produced, viscously sintered, then heat-treated in such a way that the crystallization is controlled. This powder could be a metastable system that could be rapidly quenched to enable homogenous glass formation and atomic-level mixing. This was the approach used to create $\mathrm{Al}_{2} \mathrm{O}_{3}-\mathrm{La}_{2} \mathrm{O}_{3}-\mathrm{ZrO}_{2}$ glass ceramics, by starting with flame sprayed glass beads quenched at $10^{3}{ }^{\circ} \mathrm{C} \mathrm{s}^{-1}$ in order to avoid crystallization [12]. Glass powders are then densified by sintering or hot pressing below their crystallization temperature to form a dense body, such as in traditional powder ceramic processing. Subsequent heat treatment at a higher temperature would allow for controlled crystallization. Theoretically this could result in a large crystal fraction with low amounts of residual glassy phase as was demonstrated for the aforementioned oxide system.

Alternatively, a bulk glass piece could be made that could either crystallize upon cooling or, preferably, is glassy after initial processing and is then crystallized in a controlled way upon 
further heat-treatment such as is done in traditional glass-ceramic processing. Additionally, nucleating agents may be added to increase bulk crystallization. Phase-separation could also be used deliberately to nucleate crystallization such as has been proposed for oxide systems precipitating cordierite [15], spinel [16, 65], fresnoite [66], and fluorides [67]. This method is likely to result in a reasonably low to moderate total crystal fraction, perhaps at $<50 \mathrm{vol} \%$. As has been shown in the current work, simply achieving a starting glass can be difficult for these non-traditional non-oxide systems without water quenching, and this imposes severe processing limits for scalability.

In either of the two cases presented above, having a system that forms a glass when airquenched will be preferable for flexibility in processing. In the case of traditional glass ceramic processing, a homogenous glass can be produced in a large piece then heat treated to control crystallization. Regarding the use of glass powder, having an air-quenched glass allows for the production of much larger batch sizes of glass, which could be pulverized and supplied for densification. If air-quenching is a requirement, it is apparent that the ideal glass-ceramic system for LWIR applications has not been identified from this scoping study. Some investigation into the arsenides is warranted, as they are generally much better glass-formers and have been shown to have good LWIR transmission albeit with added chemical hazards. However, the Ge-Ga-Cd$\mathrm{S}$ shows some promise in that it is relatively easy to produce a homogenous glass in this system. Finding a glass-forming system with a lower melting point $\left(T<1000{ }^{\circ} \mathrm{C}\right)$ will allow quenching without as much thermal gradient, allowing intact ingots even when water quenching as was obtainable with the chalcopyrite system Cd-Ge-As [68].

It is clear that raw materials played an important role in crystallization in the systems considered here. The $\mathrm{La}_{2} \mathrm{~S}_{3}$ raw materials were all found to contain oxygen, and the 
crystallization in the $\mathrm{Ga}_{2} \mathrm{~S}_{3}-\mathrm{La}_{2} \mathrm{~S}_{3}$ samples showed interface phases enriched in oxygen. While oxygen may be beneficial for glass-formation as shown in the literature [30], it is detrimental to LWIR transmission. Additionally, it was showed in the $\mathrm{GeS}_{2}-\mathrm{Ga}_{2} \mathrm{~S}_{3}-\mathrm{CdS}$ system that the use of elemental raw materials resulted in far superior results than sulfide precursors, presumably due to the fluxing of low-melting elemental sulfur. It is possible that with careful procedures that $\mathrm{Ga}_{2} \mathrm{~S}_{3}-\mathrm{La}_{2} \mathrm{~S}_{3}$ or $\mathrm{GeS}_{2}-\mathrm{La}_{2} \mathrm{~S}_{3}$ system glasses could be melted using elemental precursors, as pyrophoric La melts at $920{ }^{\circ} \mathrm{C}$, well below the typical maximum temperature of $1050{ }^{\circ} \mathrm{C}$ for sealed quartz ampoule experiments, and both the Ge-La and Ga-La systems have eutectics $<800$ ${ }^{\circ} \mathrm{C}[69,70]$.

Additionally, in the $\mathrm{Ga}_{2} \mathrm{~S}_{3}-\mathrm{La}_{2} \mathrm{~S}_{3}$ system, it was not clear what the effect of $R=\mathrm{Ga} /(\mathrm{La}+\mathrm{Ga})$ was on glass-formation. All samples that were not water-quenched were substantially phase-separated into what appeared to be at least three liquid phases prior to cooling, with some crystallization occurring as well. When $\mathrm{ZnS}$ was added, the targeted $\mathrm{ZnGa}_{2} \mathrm{~S}_{4}$ phase was formed, but with many other phases. When $\mathrm{CaS}$ was added, the Ca went into $\mathrm{CaGa}_{2} \mathrm{~S}_{4}$ (a phase for which there is very little literature data) as opposed to the desired $\mathrm{CaLa}_{2} \mathrm{~S}_{4}$ phase. It was apparent, however, that $\mathrm{CaS}$ was more effective in promoting glassformation in $\mathrm{Ga}_{2} \mathrm{~S}_{3}-\mathrm{La}_{2} \mathrm{~S}_{3}$ than $\mathrm{ZnS}$ at the same molar concentration.

Due to these challenges, the $\mathrm{Ga}_{2} \mathrm{~S}_{3}-\mathrm{La}_{2} \mathrm{~S}_{3}$ system does not appear to be a good candidate for LWIR glass ceramics, despite the mechanical hardness achieved that was greater than CVD $\mathrm{ZnS}$. The results for $\mathrm{GeS}_{2}-\mathrm{La}_{2} \mathrm{~S}_{3}$ can only be assessed to be preliminary, since no glasses were effectively made due to problems with volatilization. This system will likely also have oxygen contamination problems due to the inclusion of $\mathrm{La}_{2} \mathrm{~S}_{3}$, but more work should be conducted to clarify this, since very hard phases were identified that could be beneficial for mechanical 
properties. The best results were obtained with $\mathrm{GeS}_{2}-\mathrm{Ga}_{2} \mathrm{~S}_{3}-\mathrm{CdS}$ made from elemental precursors, where the uncrystallized glass had hardness in excess of CVD ZnS and transmission through the LWIR. Further studies should focus on crystallization in this system. Despite the aforementioned difficulties, there does seem to be promise in pursuing systems like these for durable LWIR glass ceramics to compete with CVD ZnS. Traditional glasses in the Ge-(As,Sb)(Se,Te) system have hardnesses of 1.0-1.4 GPa [71], compared to the glasses measured in this work which were 2-6 GPa, not including the hard phase in $\mathrm{GeS}_{2}-\mathrm{La}_{2} \mathrm{~S}_{3}$, which is competitive with other reported LWIR glass ceramics with hardness of $<3 \mathrm{GPa}$ [27]. Clearly there is much work yet to be done, as there are no reports yet of fully-ceramized sulfide-, other chalcogenide (Se or Te)-, or arsenide-based ceramics from a glass process. The advantage for making a strong LWIR material by this process is that the nucleation and growth of crystals can be controlled such that very small grains result, maximizing hardness and toughness while minimizing optical scattering.

\section{Summary and Conclusions}

Glasses were produced in the $\mathrm{Ga}_{2} \mathrm{~S}_{3}-\mathrm{La}_{2} \mathrm{~S}_{3}-(\mathrm{ZnS}, \mathrm{CaS})$ system, the $\mathrm{GeS}_{2}-\mathrm{La}_{2} \mathrm{~S}_{3}$ system, and the $\mathrm{GeS}_{2}-\mathrm{Ga}_{2} \mathrm{~S}_{3}-\mathrm{CdS}$ system. In all the compositions investigated, only those that were water-quenched formed crystal-free glasses. In the $\mathrm{Ga}_{2} \mathrm{~S}_{3}-\mathrm{La}_{2} \mathrm{~S}_{3}$ system, phase-separation was observed in all cases that were not heavily crystallized, the addition of CaS promoted phaseseparation while $\mathrm{ZnS}$ promoted crystallization, and the effect of $R=\mathrm{Ga} /(\mathrm{La}+\mathrm{Ga})$ was unclear. It is possible that $\mathrm{CaLa}_{2} \mathrm{~S}_{4}$ without substantial oxygen could be used as a precursor, but these glasses would have very high CaS levels, and it is currently unknown whether they could be water-quenched to glass. Melt homogeneity and melting temperature seems not to be the issue causing phase-separation in $\mathrm{Ga}_{2} \mathrm{~S}_{3}-\mathrm{La}_{2} \mathrm{~S}_{3}$ glasses, but rather the quench rate. The $\mathrm{GeS}_{2}-\mathrm{La}_{2} \mathrm{~S}_{3}$ 
compositions were very difficult to make, and no successful single-phase glasses were produced. It appears that compositions containing La will always be problematic, since $\mathrm{La}$ is too refractory to use as an element and the commercially available $\mathrm{La}_{2} \mathrm{~S}_{3}$ is always contaminated with some oxygen.

Glass formation in the $\mathrm{GeS}_{2}-\mathrm{Ga}_{2} \mathrm{~S}_{3}$-CdS system was much easier than other systems evaluated here, but the results were highly dependent on precursor chemicals and quench method. All glasses produced were harder than the benchmark LWIR ceramic, CVD ZnS, unlike traditional selenide-based chalcogenide glasses that are softer, and, as an added benefit, the $\mathrm{GeS}_{2}-\mathrm{Ga}_{2} \mathrm{~S}_{3}-\mathrm{CdS}$ glass had good LWIR transmission. The main critical process parameters have been identified for producing precursor glasses and are the starting materials and the quench rate. Compositions with Ge do also show some oxygen contamination, but are presumed to be much easier to purify than those with La. The Ge-based systems studied here require water quenching to form glass. Other $\mathrm{GeS}_{2}-\mathrm{Ga}_{2} \mathrm{~S}_{3}$ systems (without $\mathrm{CdS}$ ) may be an option and have been explored in the past, such as by Melling [72], who investigated Ge-Ga-S-P.

In this work the vision for a fully ceramized LWIR transmitting glass ceramic has been articulated. In the systems explored here, two contained $\mathrm{La}_{2} \mathrm{~S}_{3}$ in hopes of imparting strong bonds from this refractory sulfide and two contained $\mathrm{GeS}_{2}$ in hopes of widening the glassforming region. Methods have been demonstrated for determining optimum nucleation and growth temperatures for subsequent crystallization. The $\mathrm{Ga}_{2} \mathrm{~S}_{3}-\mathrm{La}_{2} \mathrm{~S}_{3}$ glasses do not appear to be viable candidates at this time, but $\mathrm{GeS}_{2}-\mathrm{Ga}_{2} \mathrm{~S}_{3}$ glasses appear promising.

\section{Acknowledgements}

This work was supported by the Defense Advanced Research Projects Agency in collaboration with Raytheon (DISTAR case \#22315, approved for public release, distribution 
unlimited). The views expressed are those of the author and do not reflect the official policy or position of the Department of Defense or the U.S. Government. The authors thank Paul Gassman for help with the FTIR microscope, Amy Qiao for help with the transmission measurements, and Tyler Kafentzis for help with the hardness measurements. We also thank Randy Tustison and Bill Coblenz for helpful comments and support of this work. This work was conducted in the Non-Oxide Materials Synthesis Laboratory at the Pacific Northwest National Laboratory that is operated by Battelle Memorial Institute for the DOE under contract DE-AC0576RL01830. 


\section{References}

[1] D. C. Harris, Materials for Infrared Windows and Domes: Properties and Performance, SPIE Press, Bellingham, WA (1999).

[2] J. McCloy, R. Korenstein and B. Zelinski, J. Am. Ceram. Soc. 92 (8) (2009) 1725-1731.

[3] J. S. McCloy, B. J. Riley, D. A. Pierce, B. R. Johnson and A. Qiao, Proc. SPIE 8708 (2013) $87080 \mathrm{~N}$.

[4] B. Tang, Y. Yang, Y. Fan and L. Zhang, J. Mater. Sci. Techn. 26 (6) (2010) 558-563.

[5] S. S. Bayya, J. A. Wojcik, J. S. Sanghera and I. D. Aggarwal, Proc. SPIE 4102 (2000) $169-174$.

[6] X. H. Zhang, L. Calvez, V. Seznec, H. L. Ma, S. Danto, P. Houizot, C. Boussard-Plédel and J. Lucas, J. Non-Cryst. Solids 352 (23-25) (2006) 2411-2415.

[7] C. Lin, H. Tao, R. Pan, X. Zheng, G. Dong, H. Zang and X. Zhao, Chem. Phys. Lett. 460 (1-3) (2008) 125-128.

[8] C. Lin, H. Tao, X. Zheng, R. Pan, H. Zang and X. Zhao, Opt. Lett. 34 (4) (2009) 437439.

[9] J. A. Johnson, S. Schweizer, B. Henke, G. Chen, J. Woodford, P. J. Newman and D. R. MacFarlane, J. Appl. Phys. 100 (3) (2006) 034701-034705.

[10] J. Fu, M. Kobayashi, S. Sugimoto and J. M. Parker, J. Amer. Ceram. Soc. 92 (9) (2009) 2119-2121.

[11] C. Han, M. Barta, M. Dorn, J. Nadler, R. Rosson, B. Wagner, B. Kahn and Z. Kang, Proc. SPIE 8142, (2011) 81420R-81426.

[12] A. Rosenflanz, M. Frey, B. Endres, T. Anderson, E. Richards and C. Schardt, Nature 430 (7001) (2004) 761-764. 
[13] M. Allix, S. Alahrache, F. Fayon, M. Suchomel, F. Porcher, T. Cardinal and G. Matzen, Adv. Mater. 24 (41) (2012) 5570-5575.

[14] G. H. Beall and L. R. Pinckney, J. Am. Ceram. Soc. 82 (1) (1999) 5-16.

[15] S.-M. Wang, F.-H. Kuang, Q.-Z. Yan, C.-C. Ge and L.-H. Qi, J. Alloys Compd. 509 (6) (2011) 2819-2823.

[16] C. Fernandez-Martin, G. Bruno, A. Crochet, D. Ovono Ovono, M. Comte and L. Hennet, J. Am. Ceram. Soc. 95 (4) (2012) 1304-1312.

[17] W. H. Dumbaugh, Opt. Eng. 24 (2) (1985) 257-262.

[18] S. Susman, S. Clark Rowland and K. J. Volin, J. Mater. Res. 7 (06) (1992) 1526-1533.

[19] W. B. White, D. L. Chess, C. A. Chess and J. V. Biggers, Proc. SPIE 297, (1981) 38-43.

[20] S. S. Bayya, B. B. Harbison, J. S. Sanghera and I. D. Aggarwal, Proc. 7th DoD Electromagnetic Windows Symposium (1998) 53-60.

[21] H. Ma, X. Zhang and J. Lucas, J. Non-Cryst. Solids 317 (3) (2003) 270-274.

[22] F. Xia, X. Zhang, J. Ren, G. Chen, H. Ma and J. L. Adam, J. Am. Ceram. Soc. 89 (7) (2006) 2154-2157.

[23] H. Ma, C. Laurent, B. Bruno, L. F. Marie, Z. Xianghua and J. Lucas, J. Phys. Chem. Solids 68 (5-6) (2007) 968-971.

[24] G. Delaizir, M. Dolle, P. Rozier and X. H. Zhang, J. Am. Ceram. Soc. 93 (2010) 24952498.

[25] X. Zhang, M. A. Hongli and J. Lucas, J. Non-Cryst. Solids 337 (2) (2004) 130-135.

[26] Y. Ledemi, B. Bureau, L. Calvez, M. L. Floch, M. Rozé, C. Lin, X. H. Zhang, M. Allix, G. Matzen and Y. Messaddeq, J. Phys. Chem. B 113 (44) (2009) 14574-14580. 
[27] Y. Ledemi, B. Bureau, L. Calvez, M. Roze, E. Guillevic, N. Audebrand, M. Poulain, Y. Messaddeq and X. H. Zhang, Optoelec. Adv. Mater. - Rapid Comm. 3 (9) (2009) 899904.

[28] P. N. Kumta and S. H. Risbud, J. Mater. Sci. 29 (5) (1994) 1135-1158.

[29] J. Flahaut, M. Guittard and A. M. Loireau-Lozach, Glass Technol. 24 (3) (1983) 149-156.

[30] R. Li, D. Furniss, H. Bagshaw and A. B. Seddon, J. Mater. Res. 14 (1999) 2621-2627.

[31] S. P. Morgan, D. Furniss, A. B. Seddon and M. W. Moore, J. Non-Cryst. Solids 213-214 (0) (1997) 72-78.

[32] J. Wang, D. Hewak, W. S. Brocklesby and D. N. Payne, Modifying binary $\mathrm{Ga}_{2} \mathrm{~S}_{3}-\mathrm{La}_{2} \mathrm{~S}_{3}$ glass by the addition of a third component, 10th International Non-oxide Glass Conference, Corning, NY (1996).

[33] P. Wu, X. C. He, K. Dwight and A. Wold, Mater. Res. Bull. 23 (1988) 1605-1609.

[34] K. J. Saunders, T. Y. Wong, T. M. Hartnett, R. W. Tustison and R. L. Gentilman, Proc. SPIE 683 (1986) 72-78.

[35] P. Li, W. Jie and H. Li, J. Am. Ceram. Soc. 94 (4) (2011) 1162-1166.

[36] S. P. Morgan, I. M. Reaney, R. Buckley, D. Furniss and A. B. Seddon, J. Am. Ceram. Soc. 81 (7) (1998) 1913-1918.

[37] P. N. Kumta and S. H. Risbud, Proc. SPIE 1327 (1990) 10-21.

[38] X. F. Wang, X. J. Zhao, Z. W. Wang, H. T. Guo, S. X. Gu, J. G. Yu, C. L. Liu and Q. H. Gong, Mater. Sci. Eng. B 110 (1) (2004) 38-41.

[39] X. Wang, S. Gu, J. Yu, X. Zhao and H. Tao, Mater. Chem. Phys. 83 (2004) 284-288.

[40] H. Haeuseler and C. Schmidt, J. Alloys Compd. 244 (1-2) (1996) 7-10. 
[41] N. Chbani, A.-M. Loireau-Lozac'h, J. Rivet and J. Dugué, J. Solid State Chem. 117 (1) (1995) 189-200.

[42] C. K. Lowe-Ma, D. O. Kipp and T. A. Vanderah, Mat. Res. Soc. Symp. Proc. 216 (1991) 397-402.

[43] P. N. Kumta and S. H. Risbud, J. Mater. Res. 6 (1991) 2694-2700.

[44] E. S. Sarkisov, R. A. Lidin and Y. M. Khozhainov, Izv. Akad. Nauk SSSR, Neorg. Mater. 4 (1968) 2033-2034.

[45] D. C. Harris, L. R. Cambrea, L. F. Johnson, R. T. Seaver, M. Baronowski, R. Gentilman, C. Scott Nordahl, T. Gattuso, S. Silberstein, P. Rogan, T. Hartnett, B. Zelinski, W. Sunne, E. Fest, W. Howard Poisl, C. B. Willingham, G. Turri, C. Warren, M. Bass, D. E. Zelmon and S. M. Goodrich, J. Am. Ceram. Soc. 96 (12) (2013) 3828-3835.

[46] A. Michelet, A. Mazurier, G. Collin, P. Laruelle and J. Flahaut, J. Solid State Chem. 13 (1975) 65-76.

[47] Z. V. Popovic and H. J. Stolz, phys. status sol. B 106 (1981) 337-348.

[48] C. M. Forster and W. B. White, Mater. Res. Bull. 41 (2006) 448-454.

[49] B. J. Tsay and L. H. Wang, Mater. Lett. 34 (3-6) (1998) 180-183.

[50] M. Hills, Preparation, Properties, and Development of Calcium Lanthanum Sulfide as an 8- to 12-micrometer Transmitting Ceramic, Naval Weapons Center, NWC TP 7037 (1989).

[51] J. Zhang, W. W. Chen and A. J. Ardell, Proc. SPIE 1326, (1990) 93-98.

[52] S. Barnier, M. Guittard and C. Julien, Mater. Sci. Eng. B 7 (3) (1990) 209-214.

[53] I. D. Olekseyuk, L. V. Piskach, O. V. Parasyuk, G. P. Gorgut, S. V. Volkov and V. I. Pekhnyo, J. Alloys Compd. 421 (1-2) (2006) 91-97. 
[54] H. Tao, C. Lin, S. Gu, C. Jing and X. Zhao, Appl. Phys. Lett. 91 (1) (2007) 011904.

[55] C. T. Moynihan, A. J. Easteal, J. Wilder and J. Tucker, J. Phys. Chem. 78 (26) (1974) 2673-2677.

[56] M. Repkova, P. Nemec and M. Frumar, J. Optoelec. Adv. Mtrls 8 (5) (2006) 1796-1800.

[57] A. Hrubý, Czech. J. Phys. 22 (11) (1972) 1187-1193.

[58] J. Massera, J. Remond, J. Musgraves, M. J. Davis, S. Misture, L. Petit and K. Richardson, J. Non-Cryst. Solids 356 (52-54) (2010) 2947-2955.

[59] A. Marotta, A. Buri and F. Branda, J. Mater. Sci. 16 (2) (1981) 341-344.

[60] C. S. Ray and D. E. Day, J. Am. Ceram. Soc. 80 (12) (1997) 3100-3108.

[61] H. A. Qiao, N. C. Anheier, J. D. Musgrave, K. Richardson, D. W. Hewak and N. C. Anheier, Proc. SPIE 8016, (2011) 80160F-80110.

[62] P. Boolchand, K. Gunasekera and S. Bhosle, phys. stat. solidi (b) 249 (10) (2012) 20132018.

[63] R. W. Rice, C. C. Wu and F. Boichelt, J. Am. Ceram. Soc. 77 (10) (1994) 2539-2553.

[64] E. Busch and D. Haneman, Tribol. Lett. 2 (2) (1996) 199-206.

[65] S. Chenu, E. Véron, C. Genevois, G. Matzen, T. Cardinal, A. Etienne, D. Massiot and M. Allix, Adv. Optic. Mater. 2 (4) (2014) 364-372.

[66] E. Boulay, C. Ragoen, H. Idrissi, D. Schryvers and S. Godet, J. Non-Cryst. Solids 384 (0) (2014) 61-72.

[67] T. Höche, J. Mater. Sci. 45 (14) (2010) 3683-3696.

[68] B. R. Johnson, B. J. Riley, S. K. Sundaram, J. V. Crum, C. Henager, Y. Zhang, V. Shuthanadan, C. E. Seifert, R. M. V. Ginhoven, C. Chamberlain, A. Rockett, D. Hebert and A. Aquino, J. Amer. Ceram. Soc. 92 (2009) 1236-1243. 
[69] A. B. Gokhale and G. J. Abbaschian Ge-La binary phase diagram. In: H. Baker, Editor, Alloy Phase Diagrams, ASM International, Materials Park, Ohio (1992).

[70] A. Palenzona and S. Clrafici, Bull. Alloy Phase Diagr. 11 (1) (1990) 72-77.

[71] Vitron, Vitron IR Glass Specifications.

[72] P. J. Melling, Sulfide and Phosphide Analogs of Oxynitride Ceramics, Battelle Memorial Institute, N00014-86-C0313 (1989). 


\section{Tables}

Table I. Phase analysis of sulfide raw materials

\begin{tabular}{|c|c|c|c|c|}
\hline Chemical & Supplier & Purity & XRD phase & As-analyzed \\
\hline $\mathrm{Ga}_{2} \mathrm{~S}_{3}$ & $\begin{array}{l}\text { American } \\
\text { Elements }\end{array}$ & $99.999 \%$ & $\alpha-\mathrm{Ga}_{2} \mathrm{~S}_{3}($ monoclinic $C 1 c 1)$ & \\
\hline $\mathrm{La}_{2} \mathrm{~S}_{3}$ & $\begin{array}{l}\text { American } \\
\text { Elements }\end{array}$ & $99.9 \%$ & $\begin{array}{l}\mathrm{La}_{10} \mathrm{~S}_{14.5} \mathrm{O}_{0.5} \text { (tetragonal } \\
\left.\mathrm{I}_{1} / \mathrm{acd}\right)\end{array}$ & \\
\hline $\mathrm{La}_{2} \mathrm{~S}_{3}$ & Lorad & Not stated & $\begin{array}{l}\mathrm{La}_{10} \mathrm{~S}_{14.55} \mathrm{O}_{0.45} \text { (tetragonal } \\
I 4_{1} / \text { acd) } \\
\mathrm{La}_{1.98} \mathrm{O}_{2.13} \mathrm{~S}_{0.84} \text { (hexagonal } \\
P \overline{3} m 1 \text { ) }\end{array}$ & $\begin{array}{l}\sim 96 \% \\
\text { tetragonal, } \\
\sim 4 \% \\
\text { hexagonal }\end{array}$ \\
\hline $\mathrm{ZnS}$ & Alfa Aesar & $99.99 \%$ & $\begin{array}{l}\mathrm{ZnS} \text { (cubic } F \overline{4} 3 m \text { hexagonal } \\
P 6_{3} m c \text { ) }\end{array}$ & $\begin{array}{l}\text { Likely from } \\
\text { CVD, fit } \\
\text { shows } \sim 10 \% \\
\text { hexagonal }\end{array}$ \\
\hline $\mathrm{CaS}$ & Alfa Aesar & $99.9 \%$ & $\mathrm{CaS}$ (cubic Fm3m) & \\
\hline $\mathrm{CdS}$ & Alfa Aesar & $99.999 \%$ & CdS (hexagonal $\mathrm{P}_{3} m c$ ) & \\
\hline $\mathrm{GeS}_{2}$ & $\begin{array}{l}\text { American } \\
\text { Elements }\end{array}$ & $99.999 \%$ & $\begin{array}{l}\mathrm{GeS}_{2}\left(\text { monoclinic } P{ }_{1} / c \text { or }\right. \\
\left.P 12_{1} / c l c\right) \\
\mathrm{GeS} \text { (orthorhombic Pnma) }\end{array}$ & $\begin{array}{l}\sim 75 \% \mathrm{GeS} \\
\sim 25 \% \mathrm{GeS}_{2}\end{array}$ \\
\hline
\end{tabular}


Table II. Crystal structures of lanthanide $\left(\mathrm{Ln}^{3+}\right)$ sulfides $[48,49]$.

\begin{tabular}{llcll} 
Notation & $\begin{array}{l}\text { Crystal } \\
\text { system }\end{array}$ & Space group & Alternate notation & $\begin{array}{l}\mathbf{L n}^{\mathbf{3}} \\
\text { coordination }\end{array}$ \\
\hline$\alpha$ & Orthorhombic & Pnma & $\mathrm{Gd}_{2} \mathrm{~S}_{3}$-type, A-type & $8-7$ \\
$\beta\left(\mathrm{La}_{2} \mathrm{~S}_{3}\right)$ & Tetragonal & $I 4 /$ lacd & B-type & $8-7$ \\
$\gamma\left(\mathrm{La}_{2} \mathrm{~S}_{3}\right.$ or & Cubic & $I \overline{4} 3 d$. & ${ }_{3} \mathrm{P}_{4}$-type, C-type & 8 \\
$\left.\mathrm{CaLa}_{2} \mathrm{~S}_{4}\right)$ & & & \\
$\delta$ & Monoclinic & $\mathrm{P} 2{ }_{1} / \mathrm{m}$ & $\mathrm{Ho}_{2} \mathrm{~S}_{3}$-type, D-type & $7-6$ \\
$\varepsilon$ & Trigonal & $R \overline{3} c$. & rundum-type, E-type & 6 \\
$\mathrm{La}_{2} \mathrm{O}_{3}$ & Hexagonal & $C \overline{3} m$. & & \\
$\mathrm{La}_{2} \mathrm{O}_{2} \mathrm{~S}$ & Hexagonal & $P \overline{3} m$. & & \\
\hline
\end{tabular}


Table III. Summary of sample preparation conditions. Compositions are in mole \%. All samples prepared in the box furnace were prepared in glassy carbon crucibles inside sealed silica ampoules. All samples prepared in the rocking furnace were prepared directly in silica ampoules. \# The $\mathrm{La}_{2} \mathrm{~S}_{3}$ source was Lorad, all other samples source was from American Elements. *Note these had no dwell and furnace cooled immediately after reaching temperature. Other samples had 24 hour dwell at $\boldsymbol{T}_{\text {melt }}$.

\begin{tabular}{|c|c|c|c|c|c|c|c|c|c|c|c|}
\hline Sample notation & Other ID & $\begin{array}{l}R=\mathbf{G a} / \\
(\mathbf{G a}+\mathbf{L a})\end{array}$ & $\mathbf{G e S}_{2}$ & $\mathbf{G a}_{2} \mathrm{~S}_{3}$ & $\mathbf{L a}_{2} \mathbf{S}_{3}$ & MS & M & Precursor & Furnace & $\begin{array}{l}T_{\text {melt }} \\
\left({ }^{\circ} \mathrm{C}\right)\end{array}$ & Quench \\
\hline GaLS72-10Ca-f* & GC1a & 0.72 & 0 & 65 & 25 & 10 & $\mathrm{Ca}$ & sulfides & box & 1200 & furnace \\
\hline GaLS72-10Ca-w & GC1b & 0.72 & 0 & 65 & 25 & 10 & $\mathrm{Ca}$ & sulfides & box & 1200 & water \\
\hline GaLS72-10Ca-a & GC1c & 0.72 & 0 & 65 & 25 & 10 & $\mathrm{Ca}$ & sulfides & box & 1200 & air \\
\hline GaLS72-10Ca-cw & GC1d & 0.72 & 0 & 65 & 25 & 10 & $\mathrm{Ca}$ & sulfides & box & 1200 & water $\left(800^{\circ} \mathrm{C}->\right)$ \\
\hline GaLS72-10Zn-a & GC3a & 0.72 & 0 & 65 & 25 & 10 & $\mathrm{Zn}$ & sulfides & box & 1200 & air \\
\hline GaLS72-a & $\mathrm{GC} 2 \mathrm{a}$ & 0.72 & 0 & 72.2 & 27.8 & 0 & & sulfides & box & 1200 & air \\
\hline GaLS70-f & $\mathrm{GC} 4 \mathrm{a}$ & 0.70 & 0 & 70 & 30 & 0 & & sulfides & box & 1200 & furnace \\
\hline GaLS70-a & GC4b & 0.70 & 0 & 70 & 30 & 0 & & sulfides & box & 1200 & air \\
\hline GaLS65-20Ca-w & GC6a & 0.65 & 0 & 52 & 28 & 20 & $\mathrm{Ca}$ & sulfides & box & 1200 & water \\
\hline GaLS65-20Ca-f & GC6b & 0.65 & 0 & 52 & 28 & 20 & $\mathrm{Ca}$ & sulfides & box & 1215 & furnace \\
\hline GaLS65-20Ca-a & GC6c & 0.65 & 0 & 52 & 28 & 20 & $\mathrm{Ca}$ & sulfides & box & 1300 & air \\
\hline & & Ge/La & & & & & & & & & \\
\hline GeLS-1100-a & GC5a & 0.61 & 55 & 0 & 45 & 0 & & sulfides & box & 1100 & air \\
\hline GeLS-900-a & GC5b & 0.61 & 55 & 0 & 45 & 0 & & sulfides & box & 900 & air \\
\hline GGLS-15CdS-e-w & GC7a & 2.33 & 70 & 15 & 0 & 15 & $\mathrm{Cd}$ & elements & rocking & 1050 & water \\
\hline GGLS-15CdS-s-w & GC8a & 2.33 & 70 & 15 & 0 & 15 & $\mathrm{Cd}$ & sulfides & box & 1050 & water \\
\hline GGLS-5CdS-e-w & GC10a & 9.0 & 90 & 5 & 0 & 5 & $\mathrm{Cd}$ & elements & rocking & 1050 & water \\
\hline GGLS-5CdS-e-a & $\mathrm{GC} 10 \mathrm{~b}$ & 9.0 & 90 & 5 & 0 & 5 & $\mathrm{Cd}$ & sulfides & box & 1050 & air \\
\hline
\end{tabular}


Table IV. Summary of sample characterization and visual observations.

\begin{tabular}{lllll}
\hline Sample notation & Other ID & $\begin{array}{l}\text { Visible } \\
\text { Appearance }\end{array}$ & Microstructure & Char, performed \\
\hline GaLS72-10Ca-f* & GC1a & Opaque & Large crystals & XRD, SEM \\
GaLS72-10Ca-w & GC1b & Transparent & Amorphous & XRD \\
GaLS72-10Ca-a & GC1c & Opaque & Phase-separated & XRD, SEM \\
GaLS72-10Ca-cw & GC1d & Opaque & & - \\
GaLS72-10Zn-a & GC3a & Opaque & Large crystals & XRD,SEM, hardness \\
GaLS72-a & GC2a & Opaque & Phase-separated & XRD, SEM, hardness \\
GaLS70-f & GC4a & Opaque & & XRD \\
GaLS70-a & GC4b & Opaque & Phase-separated & XRD, SEM \\
GaLS65-20Ca-w ${ }^{\#}$ & GC6a & Transparent & Amorphous & XRD, SEM, FTIR, hardness \\
GaLS65-20Ca-f & GC6b & Opaque & & - \\
GaLS65-20Ca-a & GC6c & Opaque & Phase-separated, & SEM \\
& & some crystals & \\
GeLS-1100-a & GC5a & Metallic & & XRD \\
GeLS-900-a & GC5b & Metallic & Large crystals & XRD,SEM, hardness \\
GGLS-15CdS-e-w & GC7a & Transparent & Amorphous & XRD,FTIR, index, hardness \\
GGLS-15CdS-s-w & GC8a & Metallic & & XRD \\
GGLS-5CdS-e-w & GC10a & Transparent & Amorphous & XRD,FTIR \\
GGLS-5CdS-e-a & GC10b & Metallic & & XRD \\
\hline
\end{tabular}


Table V. Phases identified by XRD with the ICSD\# and mass\% of total crystalline content (note that amorphous content was not measured).

\begin{tabular}{|c|c|c|c|c|c|}
\hline Sample \# & System & Quench & $\begin{array}{l}\text { Phase (mass\% of } \\
\text { crystalline) }\end{array}$ & & ICSD\# \\
\hline \multirow[t]{4}{*}{ GaLS72-10Ca-f (sectioned) } & Ga-La-Ca-S & Furnace & $\mathrm{CaGa}_{2} \mathrm{~S}_{4}$ & $(79.8)$ & 46017 \\
\hline & & & $\mathrm{Ga}_{2} \mathrm{~S}_{3}$ & (11.1) & 202408 \\
\hline & & & $\mathrm{La}_{3} \mathrm{~S}_{4}$ & (7.9) & 56782 \\
\hline & & & $\mathrm{La}_{3.33} \mathrm{Ga}_{6} \mathrm{~S}_{12} \mathrm{O}_{2}$ & $(1.2)$ & 32540 \\
\hline \multirow[t]{3}{*}{ GaLS72-10Ca-f (polished) } & Ga-La-Ca-S & Furnace & $\mathrm{CaGa}_{2} \mathrm{~S}_{4}$ & $(90.7)$ & 46017 \\
\hline & & & $\mathrm{Ga}_{2} \mathrm{~S}_{3}$ & (7.3) & 202408 \\
\hline & & & $\mathrm{Ga}_{2} \mathrm{O}_{3}$ & $(2.0)$ & 166199 \\
\hline \multirow[t]{4}{*}{ GaLS72-10Ca-a (polished) } & Ga-La-Ca-S & Air & $\mathrm{Ga}_{2} \mathrm{~S}_{3}$ & $(60.4)$ & 409550 \\
\hline & & & $\mathrm{CaO}$ & $(21.1)$ & 51409 \\
\hline & & & $\mathrm{Ca}_{3} \mathrm{Ga}_{4} \mathrm{O}_{7}$ & $(16.3)$ & 100356 \\
\hline & & & $\mathrm{LaS}_{1.96}$ & $(2.2)$ & 250043 \\
\hline GaLS72-10Ca-w (powder) & Ga-La-Ca-S & Water & amorphous & & - \\
\hline GaLS65-20Ca-w (powder) & Ga-La-Ca-S & Water & Amorphous & & - \\
\hline \multirow[t]{5}{*}{ GaLS72-10Zn-a (polished) } & Ga-La-Zn-S & Air & $\mathrm{Ga}_{2} \mathrm{O}_{12} \mathrm{~S}_{3}$ & (33.4) & 79304 \\
\hline & & & $\mathrm{Zn}_{3} \mathrm{~S}_{2} \mathrm{O}_{9}$ & $(25.5)$ & 15280 \\
\hline & & & $\mathrm{ZnGa}_{2} \mathrm{~S}_{4}$ & $(18.2)$ & 53604 \\
\hline & & & $\mathrm{ZnLa}_{2} \mathrm{Ga}_{2} \mathrm{OS}_{6}$ & $(22.8)$ & 61044 \\
\hline & & & $\mathrm{La}_{2} \mathrm{O}_{2} \mathrm{~S}_{2}$ & $(0.3)$ & 68498 \\
\hline \multirow[t]{4}{*}{ GaLS72-a (polished) } & Ga-La-S & Air & $\mathrm{Ga}_{2} \mathrm{~S}_{3}$ & (61.6) & 202408 \\
\hline & & & $\mathrm{GaLa}_{3} \mathrm{OS}_{5}$ & $(23.7)$ & 38067 \\
\hline & & & $\mathrm{La}$ & $(9.2)$ & 43568 \\
\hline & & & $\mathrm{La}_{2} \mathrm{O}_{3}$ & $(5.5)$ & 24693 \\
\hline \multirow[t]{3}{*}{ GaLS70-f (polished) } & Ga-La-S & Furnace & $S$ & $(63.3)$ & 15767 \\
\hline & & & $\mathrm{Ga}_{2} \mathrm{~S}_{3}$ & $(29.1)$ & 409550 \\
\hline & & & $\mathrm{LaGaS}_{3}$ & (7.6) & 27192 \\
\hline \multirow[t]{4}{*}{ GaLS70-a (polished) } & Ga-La-S & Air & $\mathrm{Ga}_{2} \mathrm{~S}_{3}$ & $(36.3)$ & 409550 \\
\hline & & & S & $(33.2)$ & 15767 \\
\hline & & & $\mathrm{LaGaS}_{3}$ & $(28.1)$ & 27192 \\
\hline & & & $\mathrm{La}_{2} \mathrm{~S}_{3}$ & $(2.4)$ & 201012 \\
\hline \multirow[t]{3}{*}{ GeLS-1100-a (ingot) } & Ge-La-S & Air & $\mathrm{Ge}_{3.33} \mathrm{La}_{6} \mathrm{~S}_{14}$ & $(53.1)$ & 636865 \\
\hline & & & $\mathrm{La}_{10} \mathrm{~S}_{14.5} \mathrm{O}_{0.5}$ & $(38.6)$ & 6002 \\
\hline & & & $\mathrm{Ge}$ & $(8.3)$ & 600774 \\
\hline \multirow[t]{2}{*}{ GeLS-1100-a (ampoule wall) } & Ge-La-S & Air & $\mathrm{GeS}$ & $(98.1)$ & 1621 \\
\hline & & & $\mathrm{Ge}$ & (1.9) & 184252 \\
\hline \multirow[t]{5}{*}{ GeLS-900-a (polished) } & Ge-La-S & Air & S & $(72.0)$ & 38147 \\
\hline & & & $\mathrm{Ge}$ & $(23.0)$ & 76146 \\
\hline & & & $\mathrm{La}_{2} \mathrm{~S}_{3}$ & $(4.0)$ & 166513 \\
\hline & & & $\mathrm{GeLa}_{2} \mathrm{~S}_{5}$ & $(1.0)$ & 42026 \\
\hline & & & Many unfit & & \\
\hline GGLS-15CdS-e-w (powder) & Ge-Ga-Cd-S & Water & Amorphous & & - \\
\hline \multirow[t]{4}{*}{ GGLS-15CdS-s-w (powder) } & Ge-Ga-Cd-S & Water & $\mathrm{Cd}_{0.36} \mathrm{Ga}_{0.64} \mathrm{~S}$ & $(53.1)$ & 108210 \\
\hline & & & $\mathrm{CdGa}_{2} \mathrm{~S}_{4}$ & (31.4) & 52801 \\
\hline & & & $\mathrm{GaS}$ & (13.2) & 202408 \\
\hline & & & $\mathrm{Ge}_{0.987} \mathrm{Ga}_{0.013}$ & $(2.3)$ & 103274 \\
\hline GGLS-5CdS-e-w & Ge-Ga-Cd-S & Water & Amorphous & & - \\
\hline GGLS-5CdS-e-a & Ge-Ga-Cd-S & Air & $\mathrm{GeS}_{2}$ & (100.0) & 31685 \\
\hline
\end{tabular}


Table VI. Hardness testing results.

\begin{tabular}{clllllll} 
Indenter & Material & Type & Load & \multicolumn{2}{c}{$\mathbf{H}_{\mathbf{v}}\left(\mathbf{k g} / \mathbf{m m}^{\mathbf{2}}\right)$} & \multicolumn{1}{c}{$\mathbf{H}_{\mathbf{v}}(\mathbf{G P a})$} \\
\hline Micro- & Clear CVD ZnS (Vitron) & Ceramic & $200 \mathrm{~g}$ & 148.3 & \pm 3.6 & 1.45 & \pm 0.04 \\
Micro- & FLIR CVD ZnS (Vitron) & Ceramic & $200 \mathrm{~g}$ & 178.3 & \pm 4.4 & 1.75 & \pm 0.04 \\
Micro- & Crystran GLS & Glass & $200 \mathrm{~g}$ & 378.1 & \pm 11.2 & 3.71 & \pm 0.11 \\
Micro- & GGLS-15CdS-e-w & Glass & $200 \mathrm{~g}$ & 248.7 & \pm 8.5 & 2.44 & \pm 0.08 \\
Micro- & GaLS65-20Ca-w & Glass & $200 \mathrm{~g}$ & 342.3 & \pm 16.7 & 3.36 & \pm 0.16 \\
Nano- & GaLS72-a & Phase-separated glass & $200 \mathrm{mN}$ & 432.0 & \pm 38.7 & 4.24 & \pm 0.38 \\
Nano- & GaLS72-10Zn-a - Phase1 & Glass ceramic & $200 \mathrm{mN}$ & 261.8 & \pm 40.2 & 2.78 & \pm 0.43 \\
Nano- & GaLS72-10Zn-a - Phase2 & Glass ceramic & $200 \mathrm{mN}$ & 527.6 & \pm 95.1 & 5.58 & \pm 1.01 \\
Nano- & GeLS-900-a - Phase1 & Glass ceramic & $50 \mathrm{mN}$ & 373.7 & \pm 63.1 & 3.95 & \pm 0.67 \\
Nano- & GeLS-900-a - Phase2 & Glass ceramic & $10 \mathrm{mN}$ & 1259.9 & \pm 13.3 & 13.3 & \pm 4.36 \\
\hline
\end{tabular}




\section{Figures}

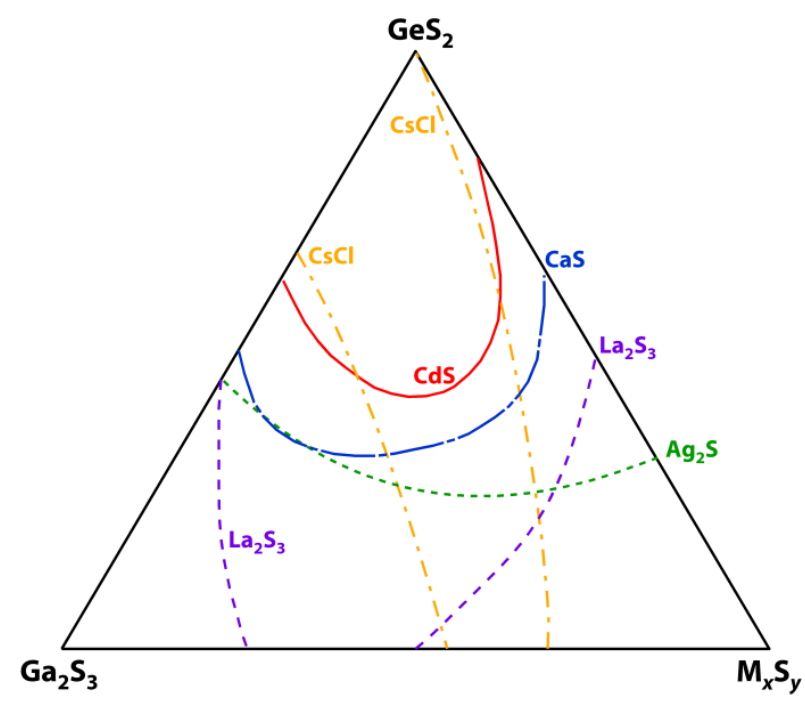

Figure 1. Glass-forming regions (in moles) in the $\mathrm{GeS}_{2}-\mathrm{Ga}_{2} \mathrm{~S}_{3}-\mathrm{Z}$ systems, where $\mathrm{Z}=\mathrm{La}_{2} \mathrm{~S}_{3}$, $\mathrm{CdS}, \mathrm{CaS}, \mathrm{Ag}_{2} \mathrm{~S}$, or CsCl.

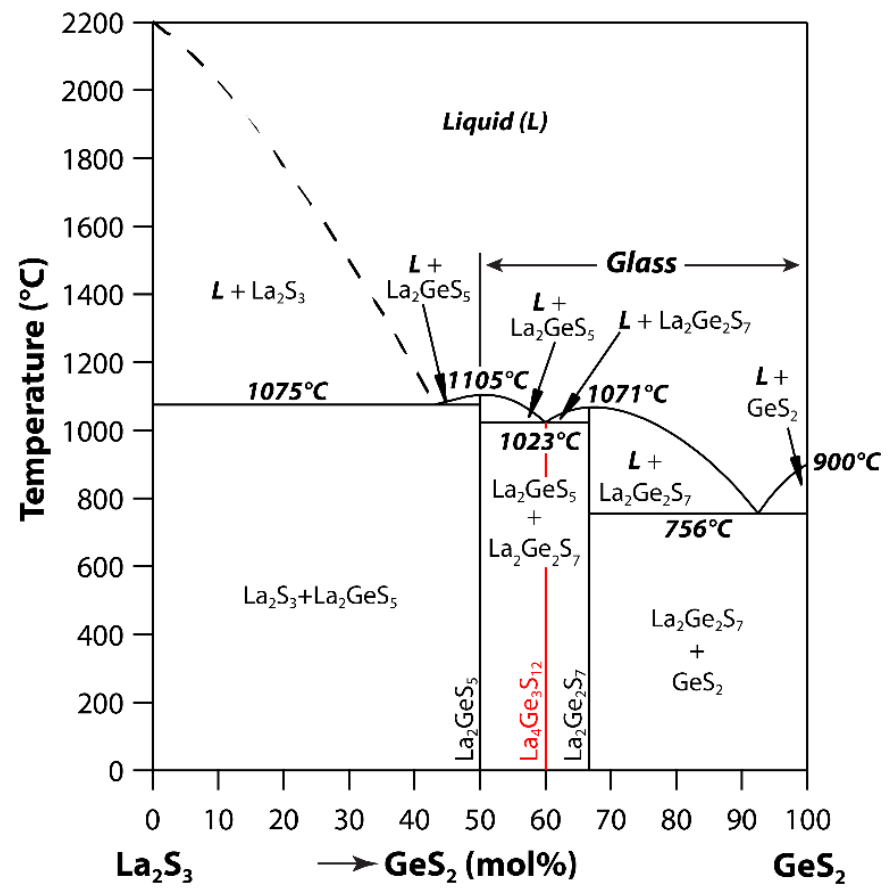

Figure 2. Binary phase diagram for $\mathrm{GeS}_{2}-\mathrm{La}_{2} \mathrm{~S}_{3}$. A vertical line has been added to reflect where $\mathrm{La}_{4} \mathrm{Ge}_{3} \mathrm{~S}_{12}$ should be. 


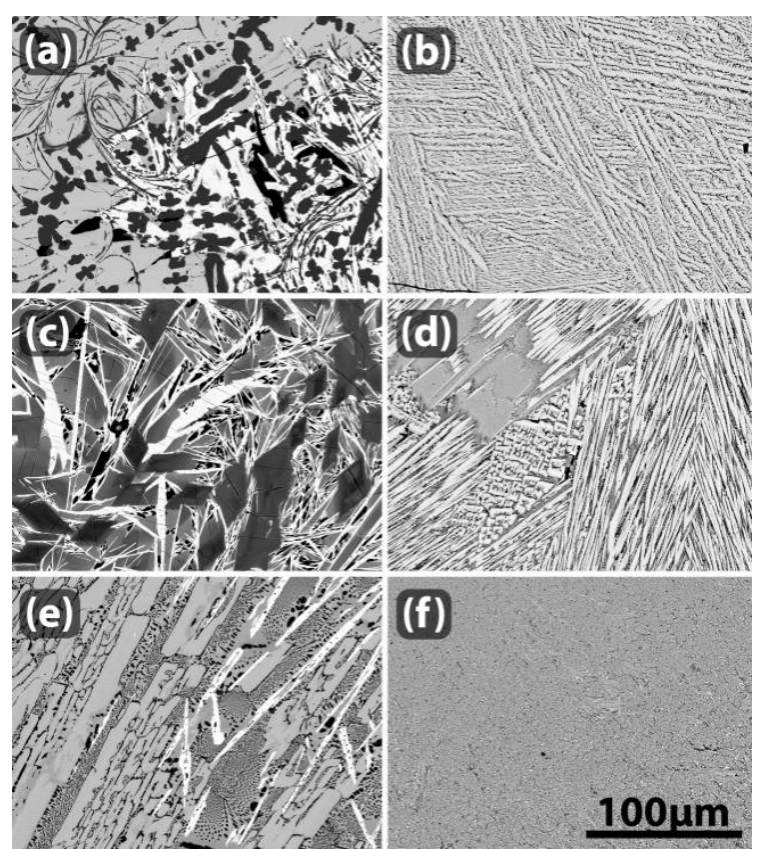

Figure 3. Microstructures of glass ceramics; note that all images are at the same magnification and are BSE images; (a) GaLS72-10Zn-a, (b) GaLS72-10Ca-a, (c) GaLS7210Ca-f, (d) GaLS72-a, (e) GaLS70-f, (f) GaLS65-20Ca-a shell area. 


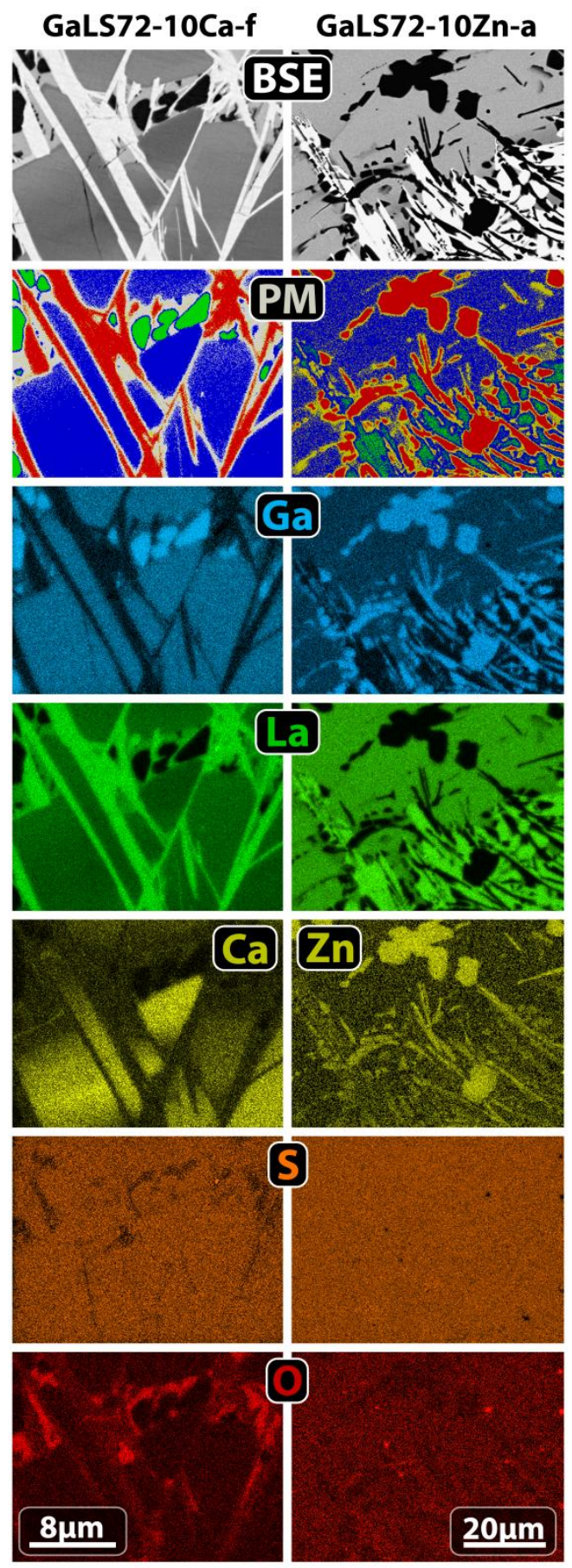

Figure 4. SEM-EDS of GaLS72-10Ca-f (furnace cool) and GaLS72-10Zn-a (air quench). BSE and phase map (PM) shown, as well as individual element maps. Note similarity in that there is an oxygen-containing interface phase (as noted in PM). In the case of the CaScontaining glass, this interface phase appears to be around the La-S crystals, while in the case of the $\mathrm{ZnS}$-containing glass, it appears to be around the $\mathrm{ZnGa}_{2} \mathrm{~S}_{4}$ crystals. 

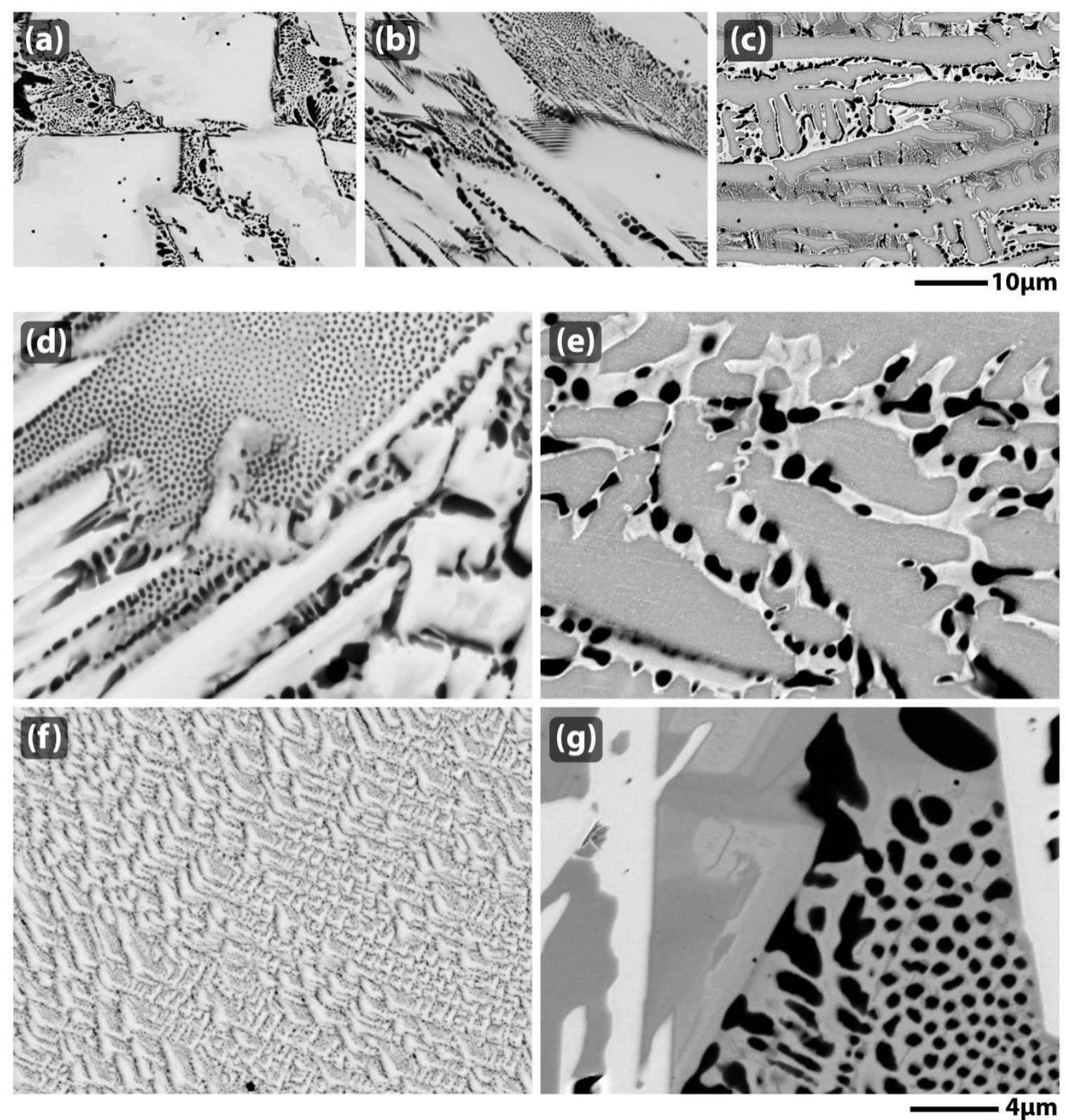

Figure 5. SEM images showing phase separation and effect of CaS and Ga:La. (a) GaLS70-a, (b) GaLS72-a, (c) GaLS72-10Ca-a, (d) GaLS72-a, (e) GaLS72-10Ca-a, (f) GaLS70-a, (g) GaLS70-f. Note that (a)-(c) are at the same scale and (d)-(g) are on the same smaller scale. In the Ga-La-S glass, the phases are either Ga-rich (dark) or La-rich (light), with the Ga-phase containing slightly more S. In the CaS-containing glass, the dark regions are Ga-S, the white regions are $\mathrm{Ca}-\mathrm{La}-$ rich, and the grey regions are Ga-rich. 


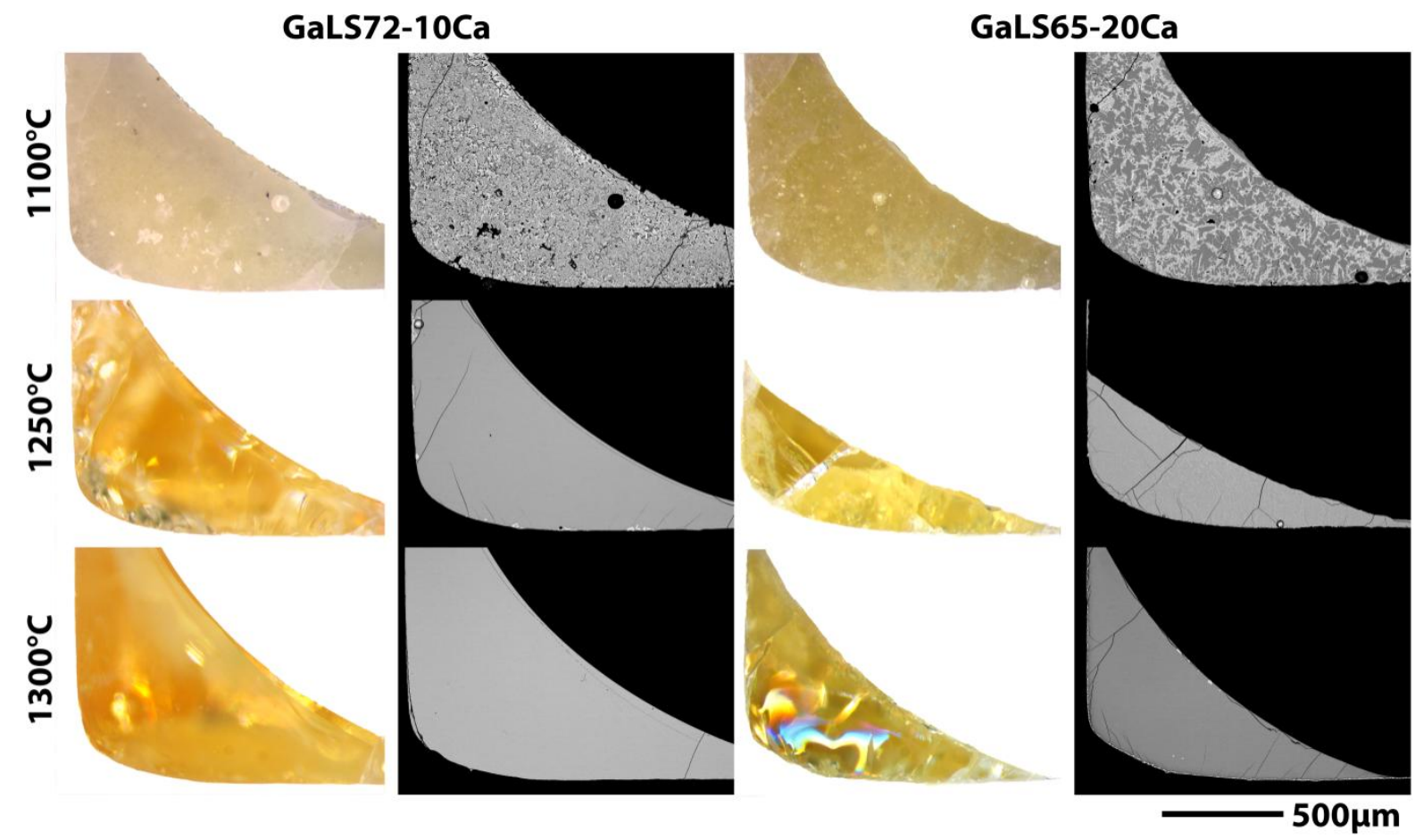

Figure 6. Optical and SEM micrographs of reheated glass in DSC pans. Starting glass powder for two columns on the left are GaLS72-10Ca-w and two columns on the right are GaLS65-20Ca-w. 

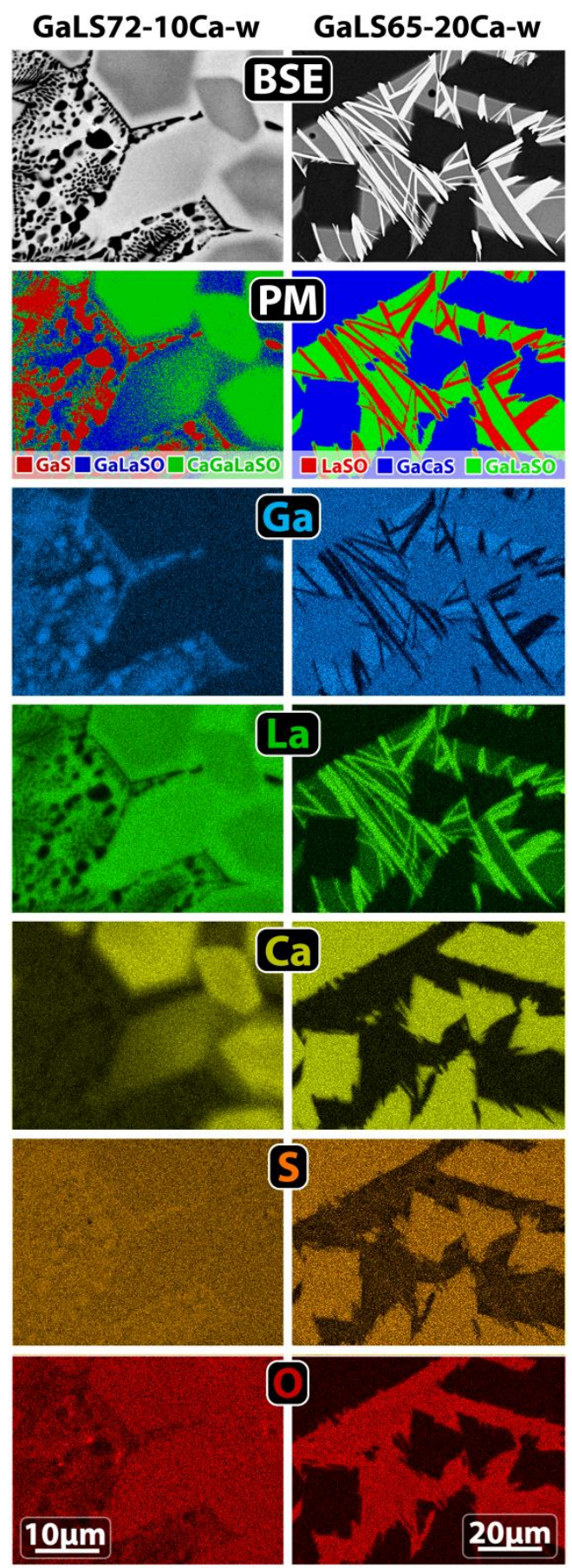

Figure 7. SEM-EDS of GaLS72-10Ca-w and GaLS65-20Ca-w glasses reheated in DSC pans to $1100{ }^{\circ} \mathrm{C}$ then cooled at $20{ }^{\circ} \mathrm{C} \mathrm{min}{ }^{-1}$. Note the presence of phase separation in the former glass versus the presence of crystallization in the latter. Both appeared to be homogenous glasses when heated to $1250{ }^{\circ} \mathrm{C}$ then cooled at $20{ }^{\circ} \mathrm{C} \mathrm{min}^{-1}$. BSE is the back-scattered electron image, PM is the phase map, and the other 5 maps show the locations of Ga, La, $\mathrm{Ca}, \mathrm{S}$, and $\mathrm{O}$. 

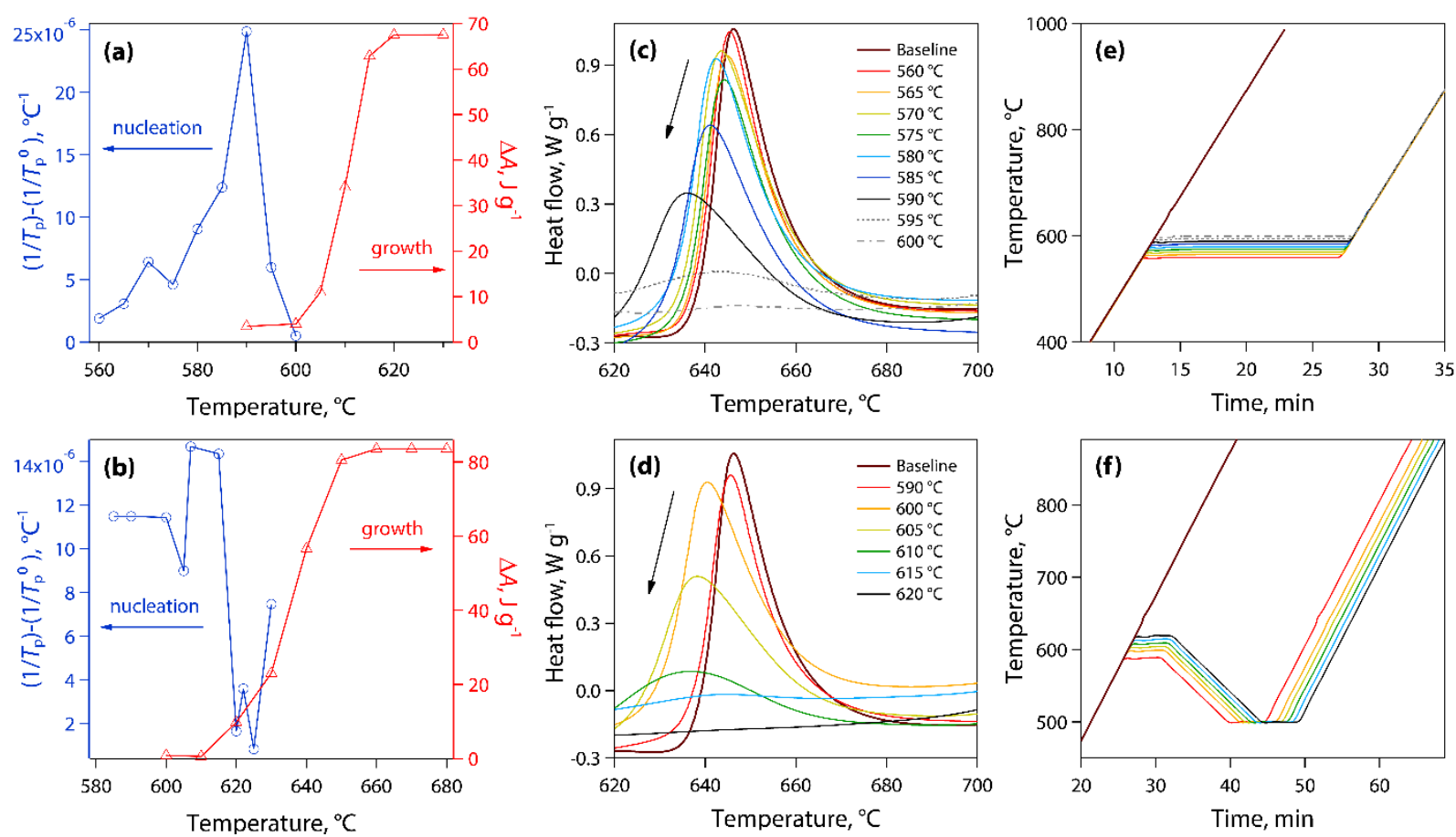

Figure 8. Thermal analysis results using DSC. Nucleation and growth curves for (a) GaLS72-10Ca-w, (b) GaLS65-20Ca-w. Raw data for GaLS72-10Ca-w determination of c) nucleation and (d) growth. Temperature profiles for determination of (e) nucleation and (f) growth. Note that legend for (c) is the same as that for (e) and legend for (d) is the same as that for (f). 
(a)

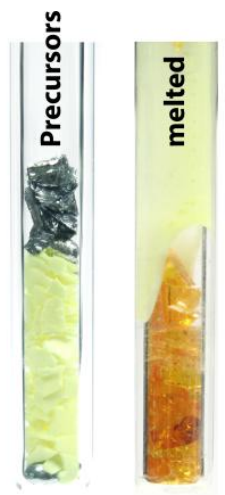

(b)

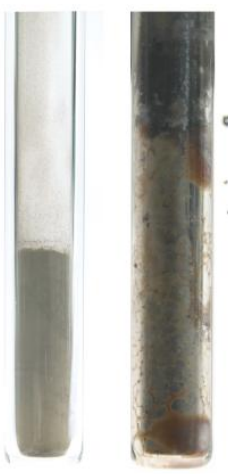

Removed from ampoule
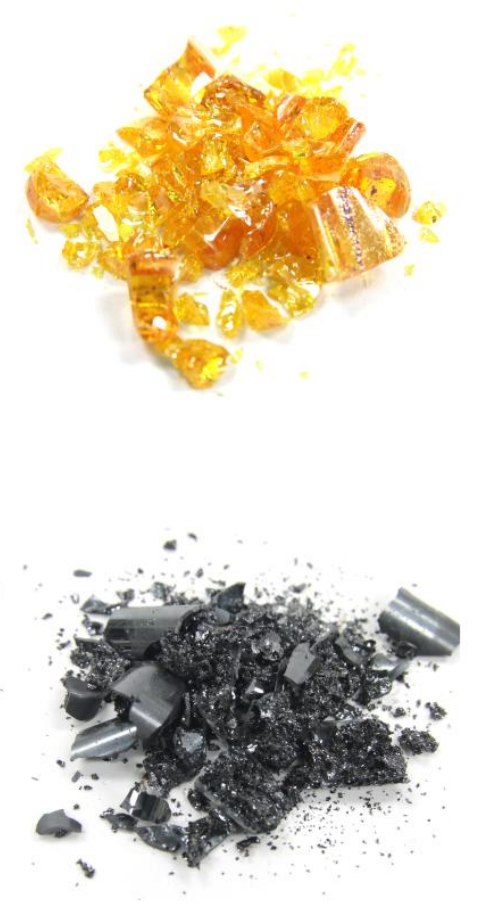

(c)

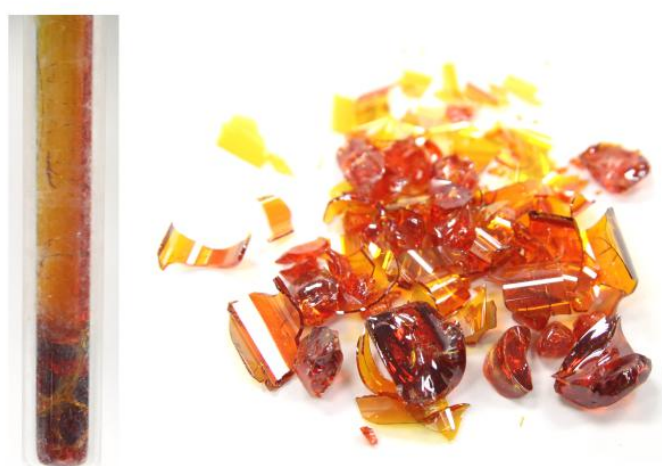

(d)

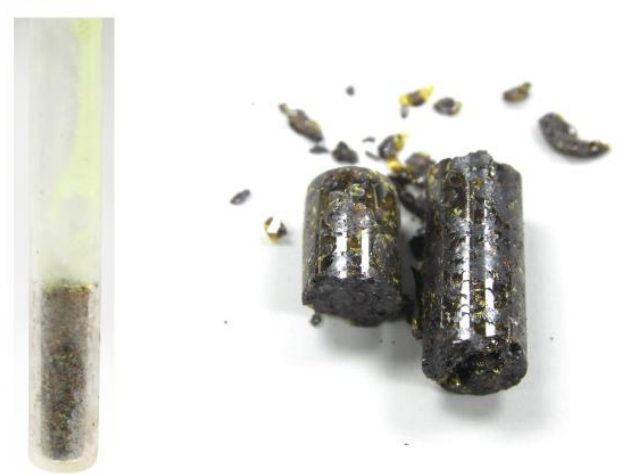

Figure 9. Photographs of Ge-Ga-Cd-S melts. (a) GGLS-15CdS-e-w (batched from elements) and (b) GGLS-15CdS-s-w (batched from sulfides) were $70 \mathrm{GeS}_{2}-15-\mathrm{Ga}_{2} \mathrm{~S}_{3}-15 \mathrm{CdS}$, and both were water quenched. (c) GGLS-5CdS-e-w (water quench) and (d) GGLS-5CdSe-a (air quench) were $90 \mathrm{GeS}_{2}-5-\mathrm{Ga}_{2} \mathrm{~S}_{3}-5 \mathrm{CdS}$, and both were batched from elements. 


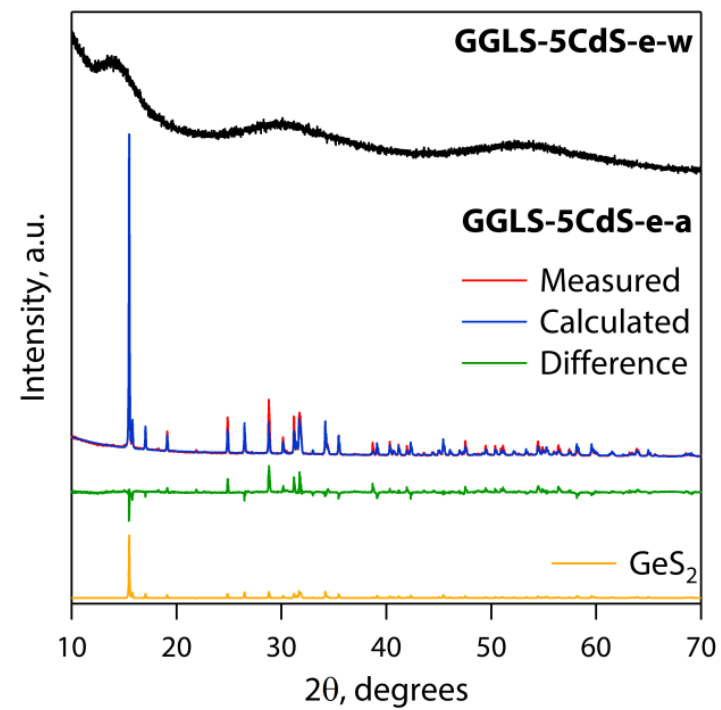

Figure 10. XRD patterns for GGLS-5CdSe-e-w (top) and GGLS-5CdSe-e-a (bottom). The scale for GGLS-5CdSe-e-w has been increased so the broad diffraction peaks (amorphous structure) can be seen more easily. The measured pattern contained some preferred orientation leading to some noticeable intensity in the difference spectrum. 


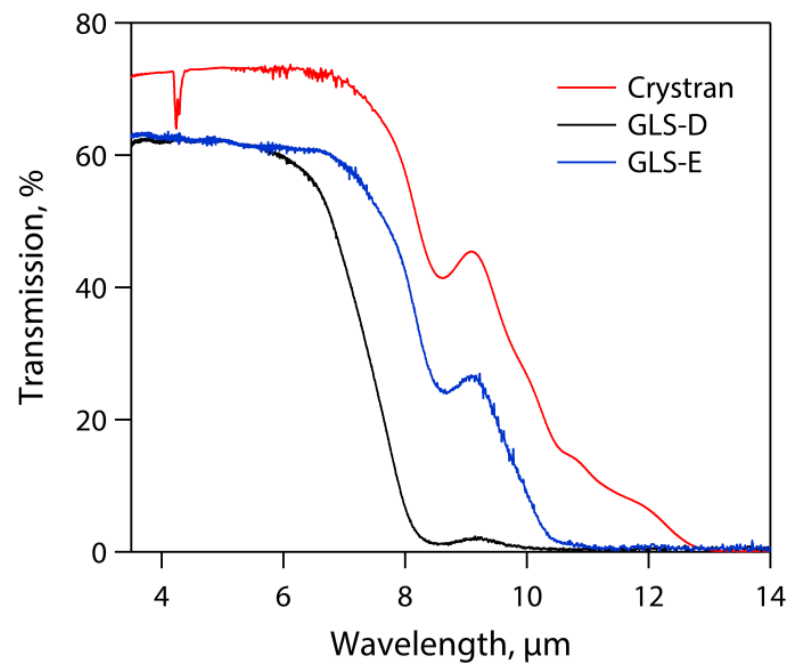

Figure 11. Infrared transmission of various Ga-La-S bulk glass disks obtained by standard FTIR, all $\sim 1 \mathrm{~mm}$ thick. Crystran glass is advertised as $5 \mathrm{~mol} \% \mathrm{La}_{2} \mathrm{O}_{3}$, while the other glasses have different unknown amounts of oxygen.

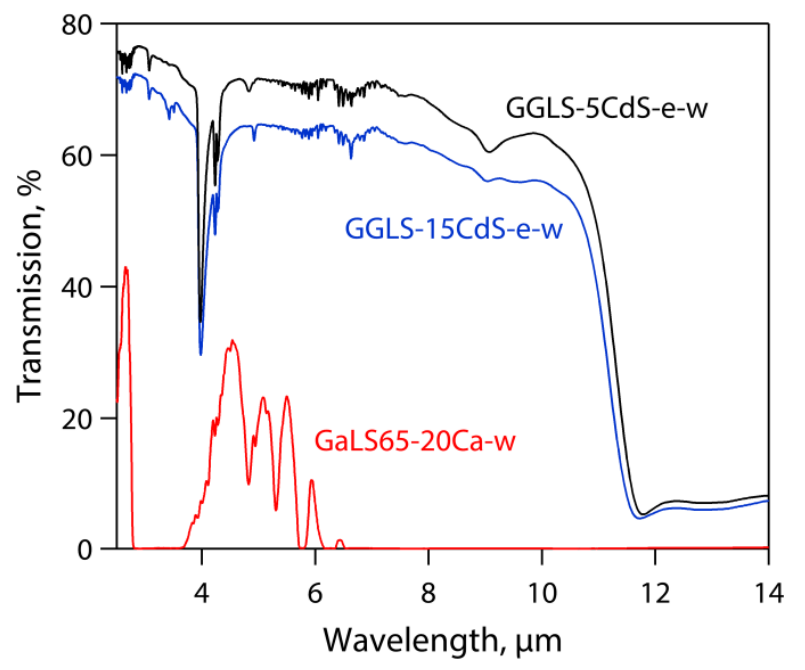

Figure 12 Infrared transmission using FTIR microscope for (1) GGLS-5CdS-e-w, (2) GGLS-15CdS-e-w, and (3) GaLS65-20Ca-w. 